\title{
ENVIRONMENTAL UNPREDICTABILITY AND ENVIRONMENTAL HARSHNESS IN EARLY LIFE: INDEPENDENT PREDICTORS OF PRESCHOOL BOYS' AND GIRLS' SELF-REGULATION
}

\author{
A Dissertation \\ presented to \\ the Faculty of the Graduate School \\ at the University of Missouri-Columbia \\ In Partial Fulfillment \\ of the Requirements for the Degree \\ Doctor of Philosophy \\ by \\ CHRISTINA SQUIRES
}

Dr. Louis Manfra, Dissertation Supervisor

JULY 2017 
The undersigned, appointed by the dean of the Graduate School, have examined the dissertation entitled

ENVIRONMENTAL UNPREDICTABILITY AND ENVIRONMENTAL HARSHNESS

IN EARLY LIFE: INDEPENDENT PREDICTORS OF PRESCHOOL BOYS' AND GIRLS' SELF-REGULATION

presented by Christina Squires,

a candidate for the degree of doctor of philosophy,

and hereby certify that, in their opinion, it is worthy of acceptance.

Professor Louis Manfra

Professor Jean Ispa

Professor Francisco Palermo

Professor Stacy Wagovich 


\section{DEDICATIONS}

I dedicate my dissertation work to my mother. You've never stopped giving. Thank you for sacrificing important things in your life so that I could take on the most important things in mine. 


\section{ACKNOWLEDGEMENTS}

I offer my sincerest gratitude to my committee for their guidance throughout this process. A special thanks to my committee chair and faculty advisor Dr. Louis Manfra for giving me the freedom to think creatively and explore my passions. I would also like to thank Dr. Jean Ispa for supplying me with the data to complete my dissertation. Thank you to my band of tireless believers who were by my side through my many failures and few successes. Your support and encouragement was worth more than I can express in words. I would also like to thank my sweetheart for all the time, care, and love you have invested in me. Finally, I would like to thank my family for believing in my when I did not believe in myself. I am grateful for you. 


\section{TABLE OF CONTENTS}

Acknowledgements

Abstract

vii

Research

1. Introduction

a. Harshness and Unpredictability as Distinct Dimensions of

Environmental Risk $\quad 2$

i. Environmental Harshness and Self-Regulation 4

ii. Environmental Unpredictability and Self-Regulation 5

iii. Pathways of Influence 9

2. The Current Study 14

$\begin{array}{ll}\text { 3. Methods } & 17\end{array}$

$\begin{array}{ll}\text { a. Sample Description } & 17\end{array}$

$\begin{array}{ll}\text { b. Measures } & 19\end{array}$

i. Environmental Unpredictability 19

1. Maternal Marital Transitions 19

2. Maternal Employment Transitions 20

3. Residential Mobility 21

ii. Environmental Harshness 21

1. Poverty Status 21

2. Average Income-to-Needs 22

3. Average Public Assistance 22 
iii. Maternal Positive Parenting Practices

1. Maternal Warmth

2. Maternal Supportiveness

3. Cognitive Stimulation

iv. Preschool Self-Regulation

1. Attention Regulation

2. Behavior Regulation

3. Emotion Regulation

v. Demographic Information

4. Results

a. Demographic Statistics and Bivariate Relations

b. Confirmatory Factor Analysis

c. Structural Regression Model

i. Model Fit

ii. Direct and Indirect Effects

iii. Multiple Group Analyses

5. Discussion

a. Environmental Unpredictability and Environmental Harshness as Independent Predictors of Self-Regulation

i. Environmental Unpredictability

ii. Environmental Harshness

iii. Domain Specific Effects

b. Limitations, Implications, and Conclusions 
$\begin{array}{lr}\text { 6. References } & 50\end{array}$

7. Appendices 63

a. Table 1: Descriptive Statistics and Bivariate Relationships 63

b. Table 2: Multiple Group Analyses 64

c. Figure 1: The Conceptual Model 65

d. Figure 2: The Measurement Model 66

e. Figure 3: The Analysis Model 67

f. Figure 4: The Analysis Model for Boys 68

g. Figure 5: The Analysis Model for Girls 69

h. Figure 6: The Analysis Model for European Americans 70

i. Figure 7: The Analysis Model for African Americans and Hispanics 71

$\begin{array}{ll}\text { 8. Vita } & 72\end{array}$ 


\section{List of Illustrations}

Tables

1. Descriptive Statistics and Bivariate Relationships

2. Multiple Group Analyses

Figures

1. The Conceptual Model 65

2. The Measurement Model 66

$\begin{array}{ll}\text { 3. The Analysis Model } & 67\end{array}$

4. The Analysis Model for Boys 68

5. The Analysis Model for Girls $\quad 69$

6. The Analysis Model for European Americans 70

7. The Analysis Model for African Americans and Hispanics 71 
Academic Abstract

Using multi-method multi-informant longitudinal data from the Early Head Start Research and Evaluation Project $(N=966)$, this study explored the effects of early-life (between 0 to 36 months) environmental unpredictability and environmental harshness on preschoolers' cognitive, behavioral, and emotional self-regulation directly and indirectly through positive parenting at 36 months. Environmental unpredictability included number of maternal employment and marital transitions and residential mobility. Environmental harshness included average income-to-needs ratios, poverty status, and receipt of public assistance. Positive parenting practices included maternal warmth, supportiveness, and cognitive stimulation. Structural equation modeling revealed that early-life environmental unpredictability and environmental harshness make independent and unique contributions to preschoolers' self-regulation. Findings also suggest that the effects of environmental unpredictability, environmental harshness, and parenting practices on children's selfregulation are domain specific and do not operate equally across all children. Environmental unpredictability was directly and negatively associated with preschoolers' emotion regulation, while environmental harshness was indirectly and negatively associated with preschoolers' attention regulation through positive parenting. These associations were only significant for boys, suggesting that boys may be more susceptible to the influence of harsh and unpredictable environments early in life.

Keywords: Self-regulation, Infancy, Early childhood, Environmental unpredictability, Environmental harshness 
Environmental Unpredictability and Environmental Harshness in Early Life: Independent Predictors of Preschool Boys' and Girls' Self-Regulation

\section{Chapter 1: Introduction}

Self-regulatory skills — the abilities needed to voluntarily control or direct one's attention, actions, and emotions - emerge within the first year of life and develop rapidly during early childhood. These skills, including attentional and behavioral control, working memory, inhibitory control, and delay of gratification, have been found to be essential for autonomous and adaptive functioning throughout the life course (Bronson, 2000). Early regulatory abilities are foundational for later school readiness and academic success (Blair \& Razza, 2007; Ponitz et al., 2008; Ponitz, McClelland, Matthews, \& Morrison, 2009), socioemotional competence (Kochanska, Murray, \& Harlan, 2000), and physical, behavioral, and mental health (Graziano, Calkins, \& Keane, 2010; Raffaelli, Crockett, \& Shen, 2010; de Riddler, Lensvelt-Mulders, Finkenauer, Stok, \& Baumeister, 2012).

Research suggests the development of self-regulation during early childhood is malleable and open to influence from the environment (Blair \& Raver, 2012; FayStammbach, Hawes, \& Meredith, 2014). Given the importance of early regulation for life-long adaptive functioning and the openness of self-regulation to environmental influence, there is a need to better understand what early environmental factors may influence the development of young children's self-regulation. This need may be especially important for children from economically disadvantaged backgrounds, who are more likely to face a confluence of negative environmental risk factors (Evans, 2004) and 
demonstrate regulatory deficits by the time they enter preschool (Blair, 2010; Raikes, Robinson, Bradley, Raikes, \& Ayoub, 2007).

The purpose of the current study was to build on previous research that has demonstrated the role of environmental factors in shaping the development of selfregulation. Specifically, the current study seeks to clarify the effects of environmental harshness (i.e., SES) and environmental unpredictability on preschoolers' self-regulation. In the current longitudinal study, I consider how exposure to harsh and unpredictable environments early in life (between ages 0 and 3 years) directly and indirectly influenced aspects of cognitive, behavioral, and emotional self-regulation in preschool among children from economically-disadvantaged backgrounds. By exploring these associations, the current study aims to uncover the extent to which environmental harshness and unpredictability independently and differentially contribute to variation in children's selfregulation.

\section{Harshness and Unpredictability as Distinct Dimensions of Environmental Risk}

In a comprehensive, cross species analysis, Ellis, Figueredo, Brumbach, and Schlomer (2009) identified two fundamental dimensions of environmental risk: environmental harshness and environmental unpredictability. Environmental harshness refers to the rate at which environmental factors cause illness and death (Belsky, Schlomer, \& Ellis, 2012; Doom, Vanzomeren-Dohm, \& Simpson, 2016; Simpson, Griskevicius, Kuo, Sung, \& Collins, 2012). In Western societies, environmental harshness is commonly indexed by indicators of socioeconomic status (SES), as lower levels of SES are linearly related to morbidity and mortality (Belsky et al., 2012; Ellis, Figueredo, Brumbach, \& Schlomer, 2009). The harsher and poorer the environment, the 
higher the incidence of illness, injury, disability, and death across all age groups within a population (Simpson et al., 2012). Harsh environments are characterized by consistently low and inadequate resources (Doom et al., 2016).

Environmental unpredictability refers to changes in salient environmental contexts that directly affect parents and/or their children (Ellis et al., 2009). Such changes include residential moves, changes in the employment status of parents, and parental transitions, such as marriage and divorce (Belsky et al., 2012; Simpson et al., 2012). Unpredictable environments are characterized by frequent, rapid, and/or random changes in and around the family (Belsky et al., 2012).

According to the evolutionary life history model proposed by Ellis and associates (2009), environmental harshness and environmental unpredictability are conceptually distinct dimensions of environmental risk that may exert unique and additive influences on development. Environments that are harsh may confer different effects on human development than environments that are unpredictable (Doom et al., 2016; Simpson et al., 2012). Evidence for this is found in studies examining the influence of harsh and unpredictable environments on risk-taking behaviors and life history outcomes in adolescent and adult samples. For instance, Doom, Vanzomeren-Dohm, and Simpson (2016) concluded that exposure to unpredictable environments (indexed by changes in maternal employment, residence, and cohabitation) from birth to age 5 was associated with adolescent substance abuse and externalizing behaviors above and beyond the effects of harshness (i.e., SES) experienced early in life. Similarly, Belsky, Schlomer, and Ellis (2012) reported that environmental unpredictability, beyond the influence of harshness alone, uniquely predicted number of sexual partners at age 15. Environmental 
harshness and environmental unpredictability were also independently associated maternal depressive symptoms and maternal sensitivity (Belsky et al., 2012).

Researchers examining these environmental factors in relation to children's selfregulation have provided important insight into how children's self-regulation may be affected by harsh and unpredictable environments. Research on each is reviewed below.

\section{Environmental Harshness and Self-Regulation}

Many studies have demonstrated that environmental harshness is negatively associated with children's self-regulation (Blair, 2010; Blair \& Raver, 2012; Bradley \& Corwyn, 2002; Raikes et al., 2007). In environments with consistently low and inadequate economic resources, children's ability to regulate their thoughts, emotions, and behaviors is likely to be compromised (Blair \& Raver, 2012; Evans \& Kim, 2013; Mistry \& Wadsworth, 2011; Wanless, McClelland, Tominey, \& Acock, 2011). For instance, using the Head-to-Toes task as a behavioral assessment of self-regulation, Wanless, McClelland, Tominey, and Acock (2011) concluded that children from lowincome families began prekindergarten with significantly lower self-regulation than their economically-advantaged peers. Similarly, Sektnan, McClelland, Acock, and Morrison (2010) found that children in families with low income-to-needs ratios had lower regulatory skills at 54 months of age than their more affluent counterparts. Indeed, children from low-income families have been found to demonstrate deficits across several domains of self-regulation, including cognitive self-regulation (e.g., attentionalcontrol problems; Evans \& Kim, 2013), behavioral self-regulation (e.g., poorer impulse control; Mistry \& Wadsworth, 2011), and emotional self-regulation (e.g., higher reactivity; Raver, 2004). 
Exposure to harsh environments may directly influence children's self-regulation through the development of stress response physiology (Blair \& Raver, 2012; Hackman \& Farah, 2009). In harsh environments, children must contend with a host of chronic stressors that have the potential to alter the structure and connectivity of stress response systems, including the hypothalamic-pituitary-adrenal axis and the autonomic nervous system (Blair, 2010; Blair \& Raver, 2012). These alterations, in turn, lead to changes in stress hormone levels that drive synaptic activity in the neural systems important for selfregulation, including the prefrontal cortex (PFC; Holmes \& Wellman, 2009). In harsh environments, stress response systems and, subsequently, the connectivity of brain regions that underlie self-regulation may develop in ways that promote reactive rather than reflective self-regulation (Diamond, Campbell, Park, Halonen, \& Zoladz, 2007; Segal, Richter-Levin, \& Maggio, 2010).

\section{Environmental Unpredictability and Self-Regulation}

Compared to the number of investigations examining the association between environmental harshness/SES and children's regulatory abilities, there is much less research on the relation between environmental unpredictability and children's selfregulation. The vast majority of studies exploring this association have only included one indicator of environmental unpredictability (e.g., residential mobility; Roy, McCoy, \& Raver, 2014). The few that have included more than one indicator have only examined environmental unpredictability within the context of the household (i.e., household instability defined as frequent changes in the composition of the household, including residential moves and general changes in the people who live in the household, including the mother and father; McCoy \& Raver, 2014). Results from these investigations are 
mixed. Some have found no relation between aspects of environmental unpredictability and children's self-regulation (e.g., Vernon-Feagans, Willoughby, \& Garret-Peters, 2016), while others report that experiences with environmental unpredictability have a negative impact on children's regulatory abilities (e.g., McCoy \& Raver, 2014).

McCoy and Raver (2014) reported that preschool children from economicallydisadvantaged backgrounds who experienced two or more indicators of household instability (e.g., residential moves, family member moves into the household, family member gets married or divorced/separated) in one year demonstrated lower levels of effortful control on a delay of gratification task at the end of that year. Children who experienced high levels of environmental unpredictability also demonstrated lower levels of assessor-rated global attention and impulse control (i.e., concentration, distractibility, impulsivity, and regulation of arousal; McCoy \& Raver, 2014). Interestingly, no significant relation was found between household instability and measures of children's cognitive self-regulation (i.e., the pencil tap task and balance beam task), suggesting that household instability may influence some, but not all, dimensions of self-regulation (McCoy \& Raver, 2014).

Studies examining the effects of residential mobility on children's self-regulation provide some additional support for the negative association between aspects of environmental unpredictability and regulatory skills. For instance, Schmitt, Finders, and McClelland (2015) found that residential mobility (operationally defined as number of moves in the past 5 years) experienced by children from economically-disadvantaged backgrounds was negatively associated with inhibitory control in preschool (using the day-night Stroop task; Gerstadt, Hong, \& Diamond, 1994). Similarly, Lengua, Honorado, 
and Bush (2007) reported a negative association between the number of residential moves children experienced through preschool and effortful control measured with five laboratory tasks during preschool. This association remained significant after controlling for effortful control prior to preschool.

Other studies have not found support for the negative relation between environmental unpredictability and self-regulation. For example, Vernon-Feagans and colleagues (2016) concluded that among low-wealth rural families, household instability experienced during the first three years of life did not significantly predict performancebased behavioral regulation (assessed via the Head-to-Toes task; Ponitz et al., 2008, and the Puzzle Box task; Feagans \& Farran, 1981; Feagans \& Short, 1986) or teacher-rated dysregulation (i.e., ADHD and hyperactivity) during preschool (Vernon-Faegans et al., 2016). Similarly, Raver, Blair, and Garrett-Peters (2015) reported that exposure to household instability from infancy to early childhood (from 6 to 58 months of age) was not significantly related to parent report of children's difficulty regulating negative emotions at 58 months. One possible explanation the authors offered for these finding was that household instability is not experienced daily by children, and thus, may not have a strong of effect on children's development (Vernon-Faegans et al., 2016).

With inconsistent findings in this small body of literature, it is not clear if environmental unpredictability compromises children's ability to regulate their actions, thoughts, and emotions. Limitations in the measurement of environmental unpredictability, including having only one indicator of unpredictability or multiple indicators in only one context, further limit the extent to which conclusions about environmental unpredictability and self-regulation can be made. Although it is known 
that many children from low-income families experience frequent changes in their family ecology (Evans, 2004; Dalaker, 2001), more research is needed to clarify the role of environmental unpredictability in the development of self-regulation.

It is possible that exposure to environmental unpredictability early in life makes it difficult for children to build a predictable model of their environment, and instead, causes children to develop an unpredictability schema-a view of the world as chaotic and unreliable (Cabeza de Baca, Barnett, \& Ellis, 2016). With this view, children may be more likely to adopt a present time orientation, which is characterized by behaviors reflective of poor self-regulation, including impulsivity, a preference for immediate rewards, discounting of the future, high levels of vigilance, reactive responses to stimuli, and little deliberation when making decisions (Ellis et al., 2009; Frankenhuis, Panchanathan, \& Nettle, 2016; McGuire \& Kable, 2013).

While on the surface it may seem that such characteristics are maladaptive, researchers have concluded poor self-regulation in unpredictable contexts may in fact be adaptive and bring about important advantages (Fawcett, McNamara, Houston, 2012; Griskevicius, Tybur, Delton, \& Robertson, 2011). From an evolutionary perspective, children have evolved to develop in ways that best fit the kinds of challenges and opportunities present in their environment (Belsky et al., 2012). In unpredictable environments where threats may appear without warning, frequent unexpected changes may occur, and opportunities may be short-lived, impulsive individuals may be better equipped to make quick decisions and take advantage of unexpected opportunities that optimize survival (Daly \& Wilson, 2005; Mittal, Griskevicius, Simpson, Sung, \& Young, 2015). Accordingly, poor self-regulation in unpredictable contexts might be adaptive by 
promoting greater vigilance to detect threats and opportunities, as well as quicker reactions to respond promptly and capture immediate rewards (Mittal et al., 2015).

\section{Pathways of Influence}

Consistent with the bioecological model (Bronfenbrenner \& Morris, 2006), it is likely that more proximal factors account for the influence of more distal factors on children's development. Indeed, several researchers examining the effects of SES on children's development have underscored the importance of testing for mediators and have concluded that the inclusion of mediators often accounts for much of the effect of SES on the outcome under investigation (e.g. Linver, Brooks-Gunn, \& Kohen, 2002).

Many empirical investigations have focused on the mechanisms through which SES influences development (e.g., Evans \& English, 2002; Lengua et al., 2014; Linver et al., 2002). With growing recognition that self-regulation develops within the social context of the family (Carlson, 2009; Feldman \& Klein, 2003), researchers have begun to explore early relational experiences in the family context as potential mediators of the association between environmental harshness and children's self-regulation. Parenting practices, including parental warmth, supportiveness, and cognitive stimulation, have been consistently linked with children's self-regulation.

Parenting practices, which tend to be less warm and supportive in low-SES contexts (Evans, Boxhill, \& Pinkava, 2008; Lengua et al., 2014), serve as a key mechanism through which environmental harshness negatively influences the development of self-regulation during early childhood (Choe, Olson, \& Sameroff, 2013). For instance, Blair and colleagues (2011) concluded that among a sample of predominately low-income children and mothers, maternal education (an indicator of 
SES) was indirectly associated with 3-year-old children's self-regulation through positive (i.e., high levels of sensitivity, positive regard, animation, and stimulation, and low levels of detachment) and negative (i.e., high levels of intrusiveness and negative regard) parenting. Negative parenting also mediated the association between income-to-need ratios and self-regulation, such that lower income-to-need ratios were associated with higher levels of negative parenting, which in turn were associated with poorer selfregulation (Blair et al., 2011).

Parenting practices in harsh environments also tend to be substantially less cognitively stimulating (Linver et al., 2002). Low-income parents speak to their children less often and in less sophisticated ways than parents of higher SES (Hart \& Risley, 1995; Hoff, Laursen, \& Tardif, 2002). Parents from low-income backgrounds are also less likely to read to their children on a daily basis (Wallman, 2008) or engage in behaviors that promote and support learning (e.g., encouragement to learn shapes, numbers, and letters; Evans, 2004). Such practices have been associated with the development of children's self-regulation (Bradley \& Corwyn, 2002).

For instance, utilizing a sample of low-income children and families, ChazanCohen et al. (2009) concluded that a stimulating home learning environment, as measured by the support for learning and literacy subscale of the Home Observation for Measurement of the Environment (HOME), was associated with higher levels of emotional regulation among preschool children. This subscale captures observed motherchild interaction, the availability of age-appropriate materials intended to provide stimulation (e.g., books), and maternal reports of their own actions to provide cognitive stimulation (e.g., reading to their children; Fuligni, Han, \& Brooks-Gunn, 2004). 
Similarly, utilizing the same subscale of the HOME, Mezzacappa, Buckner, and Earls (2011) reported that children who experienced higher levels of parental cognitive stimulation during infancy demonstrated higher levels of cognitive control, a core component of self-regulation, during childhood. This association was significant while controlling SES, suggesting that cognitive stimulation influences aspects of selfregulation above and beyond the effects of low SES alone.

In harsh home environments, parents are more likely to experience high levels of distress which can reduce their ability to engage in warm, supportive, and stimulating interactions with their children (Conger \& Donnellan, 2007). Reduced parental warmth, supportiveness, and stimulation may, in turn, lead to regulatory deficits in children (Bernier, Carlson, \& Whipple, 2010; Blair, Raver, \& Berry, 2014; Choe et al., 2013; Lengua et al., 2014; Von Suchodoletz, Trommsdorff, \& Heikamp, 2011). In harsh home environments with lower parental warmth and supportiveness as well as fewer educational materials and stimulating experiences, children may not be presented with opportunities to practice behaviors that are foundational to the development of selfregulation (Sektnan, McClelland, Acock, \& Morrison, 2010). Comparatively, in the presence of warm, supportive, and stimulating parenting practices, children may be better able to appropriately modulate their levels of arousal and reactivity, which may put them in states that are easier to regulate. Warm and supportive caregivers may also serve as effective models of appropriate regulation (Choe et al., 2013).

Very few studies have explored the mechanisms through which environmental unpredictability shapes the development of self-regulation. In fact, only one study to my knowledge specifically examined a potential mediator of the relation between 
environmental unpredictability and self-regulation among children. Using parent responsivity/acceptance as a mediator of the relation between household instability in the first three years of life and preschool self-regulation, Vernon-Feagans and colleagues (2016) did not find any direct or indirect associations among household instability, parenting practices, and children's behavioral self-regulation. Despite this finding, it is reasonable to expect that, like environmental harshness, environmental unpredictability might disrupt parenting processes that facilitate optimal development of children's selfregulation (Evans, Gonnella, Marcynyszyn, Gentile, \& Salpekar, 2005). Studies examining environmental unpredictability with outcomes other than self-regulation seem to support this conclusion.

For instance, Belsky et al. (2012) reported that environmental unpredictability (indexed by paternal transitions, household moves, and parental employment transitions) experienced from birth to age five years was significantly associated with maternal depressive symptoms and maternal sensitivity. Families who experienced greater environmental unpredictability in the first five years of their children's lives tended to experience higher levels of maternal depressive symptoms when children were 54 months old and less maternal sensitivity when children were in first and third grade (Belsky et al., 2012). Several other indicators of environmental unpredictability, including partnership transitions (e.g., Beck, Cooper, McLanahan, \& Brooks-Gunn, 2010) and changes in employment (e.g., McLoyd, Jayaratne, Ceballo, \& Borquez, 1994) have also been associated with diminished parenting quality. It is likely that frequent changes in family ecology generate significant stress as families work to renegotiate family rules and reorganize family roles (Beck et al., 2010). 
Much like the stress that accompanies environmental harshness, unpredictabilityrelated stress may interfere with caregivers' abilities to respond sensitively to their children's needs and model competent coping and regulatory strategies for their children (McCoy \& Raver, 2014). Parenting in turn may be the more proximal casual variable between environmental unpredictability and children's regulatory skills. While it is plausible that environmental unpredictability influences self-regulation via parenting processes, more research is needed to understand the potential mechanisms through which environmental unpredictability shapes children's developing regulatory skills. 


\section{Chapter 2: The Current Study}

Despite evidence that environmental harshness and unpredictability are conceptually distinct dimensions of environmental risk, and that development of selfregulation during childhood may be compromised in harsh and unpredictable environments, the literature lacks an explicit attempt to distinguish and compare the direct and indirect effects of harsh and unpredictable environments on children's selfregulation. Although some research has controlled for poverty while examining the effects of environmental unpredictability on regulatory skills (McCoy \& Raver, 2014; Vernon-Faegans et al., 2016), this research has not included an assessment of overall environmental unpredictability that extends beyond a single indicator or beyond multiple indicators in a single context.

The inclusion of only one indicator or of multiple indicators in only one context is adequate if the goal of the study is to examine how a specific indicator of environmental unpredictability, or how environmental unpredictability in a specific context, affects children's self-regulation. These approaches, however, should not be viewed as a complete approach to understanding the overall impact of environmental unpredictability on children's regulatory abilities (Belsky et al., 2012). A more comprehensive approach involves creating a latent construct of environmental unpredictability, as has been done in studies exploring the influence of harsh and unpredictable environments on life history strategies (e.g., Doom et al., 2016; Simpson et al., 2012), with multiple relevant, multicontextual indicators (Belsky et al., 2012).

W2ithout a specific comparison of the direct and indirect effects of harsh and unpredictable environments on children's self-regulation, it is not known if 
environmental unpredictability and environmental harshness make independent and/or differential contributions to children's regulatory competence or if one exerts a greater influence on the development of self-regulation. It is also not clear if both environmental unpredictability and environmental harshness indirectly influence self-regulation through more proximal mechanisms. The primary goal of the current longitudinal study was to fill these gaps. Clarifying the possibly specific and independent influence of harsh and unpredictable environments on self-regulation is critical for understanding children's functioning in the context of poverty and for informing preventative interventions for children growing up in difficult environments.

Studying the effects of environmental unpredictability and environmental harshness during the first three years of life may be especially important given research that suggests exposure to risk in early childhood has greater consequences for long-term development than exposure to risk later in childhood (Maholmes \& King, 2012). Because self-regulation develops rapidly during early childhood, exposure to environmental unpredictability and/or environmental harshness within the first three years of life may disrupt the development of core components of self-regulation that form the foundations on which later regulatory abilities are built (Bronson, 2000). This may be particularly true if environmental unpredictability and environmental harshness influence self-regulation through mediators at the family level (e.g., parenting practices). The home/family environment may be more closely linked to the development of self-regulation for young children than to that of older children, who may have more opportunities outside of the home to develop and/or practice regulatory skills (Maholmes \& King, 2012). 
The current longitudinal study sought to extend the existing literature on

environmental unpredictability and environmental harshness and children's development of self-regulation by pursuing the following objectives:

1. Examine how exposure to environmental unpredictability and environmental harshness experienced during the first three years of life directly influences aspects of cognitive, behavioral, and emotion regulation in preschool;

2. Explore how exposure to environmental unpredictability and environmental harshness experienced during the first three years of life indirectly influences aspects of cognitive, behavioral, and emotion regulation through positive parenting practices observed when children were 36 months old.

Based on Ellis and associates' (2009) evolutionary life history model, it was expected that environmental harshness and environmental unpredictability would be dissociable, and thus, developmental exposure to harsh and unpredictable environments would independently contribute to variation in children's self-regulation. Consistent with previous research (e.g., Choe et al., 2013; Evans et al., 2005; Linver et al., 2002) and theory (Bronfenbrenner \& Morris, 2006), it was also expected that effects of environmental harshness and environmental unpredictability on self-regulation would at least be partially accounted for by positive parenting. 


\section{Chapter 3: Method}

\section{Sample Description}

To accomplish the objectives of the current study, data from the Early Head Start Research and Evaluation Project (EHSREP) were analyzed. The EHSREP was a 17-site randomized experimental evaluation, for which data were collected from 1996 to 2001. All participants were parents and children from low-income families who applied for services through Early Head Start (EHS) agencies. Only families who were pregnant or had a child younger than a year old by the time they applied for EHS services were eligible to participate. A total of 3001 mothers and their EHS-eligible children (referred to as "focus children" throughout this paper) were recruited for the EHSREP. Half the families were randomly assigned to the program at the time of application $(n=1513)$. The remaining half were assigned to the comparison group $(n=1488)$. Focus children ranged in age from pre-birth (i.e., one-fourth of families enrolled while pregnant with the focus child) to one year at the time of random assignment.

Baseline interviews were conducted when participants applied to receive services. Additional interviews and assessments were later conducted following two data collection schedules. The first schedule was based on the number of months since random assignment. Parent Service Interviews (PSIs) were conducted over the phone 6, 15, and 26 months after random assignment. Because PSIs were scheduled based on date of random assignment and focus children were between pre-birth and one year at the time of random assignment, children's chronological age varied at PSI data collection time points. 
The second data collection schedule was based on the age of focus children. Interviews, observations, and child assessments were conducted when focus children were approximately 14, 24, and 36 months old and during prekindergarten (i.e., the spring prior to kindergarten entry). On average, the 6-, 15-, and 26-month PSIs were conducted five months before the 14-, 24-, and 36-month chronological-age-based assessments, respectively.

Variables used in the current study were drawn from baseline interviews, 6-, 15-, and 26-month PSIs, observations and assessments conducted when focus children were 36 months old, and prekindergarten child assessments. For the purposes of the current study, the sample was limited to families of focus children who (a) were 36 months or younger at the time of the 26-month PSI and (b) had prekindergarten follow-up data. Of the initial 2,087 families with data available for all study variables, 1,675 were 36 months or younger at the time of the 26-month PSI. Of these 1,675 children, 966 had follow-up data at prekindergarten. Based on these criteria, a final sample of 966 families and focus children were selected from the EHSREP for the current study. The final sample comprised of $49 \%$ girls with a mean age of 29.6 months $(S D=4.6)$ at 26 months after random assignment.

Sample comparisons were conducted to determine if the current sample $(N=966)$ differed on demographic characteristics from those from the EHSREP sample excluded from the current study $(N=1,121)$. Analyses revealed that those included in the current sample did not significantly differ from those excluded from the current sample on maternal education, $t(1700)=-1.53, p=.126$, income, $t(2500)=-1.50, p=.134$, child sex, $\chi^{2}(1, N=1861)=.00, p=.984$., or program (control, Early Head Start) group, $\chi^{2}(1$, 
$N=2087)=.12, p=.728$. Those included in the current sample did significantly differ from those excluded on ethnicity, $\chi^{2}(3, N=2087)=13.36, p<.01$. The current sample has fewer African American children (33\% compared to 36\%) and Hispanic children ( $22 \%$ compared to $25 \%$ ), and more European American children (42\% compared to 34\%) compared to those excluded from the current sample.

\section{Measures}

Multiple indicators were drawn from the dataset to assess early-life environmental unpredictability, early-life environmental harshness, maternal positive parenting, and child attention, emotion, and behavior regulation. These constructs are described in detail below.

Environmental unpredictability. As in other studies (Belsky et al., 2012; Simpson et al., 2012), environmental unpredictability was indexed by changes in the salient environmental contexts directly affecting parents and/or their children. Three indicators, maternal marital transitions, maternal employment transitions, and residential mobility during focus children's first three years of life were used to assess environmental unpredictability.

Maternal marital transitions. Mothers indicated one of the following marital statuses at 6, 15, and 26 months after random assignment: Never married, not living together unmarried, Married, Separated, Divorced, Widowed, or Living together, unmarried. Marital transitions was calculated as the number of changes in marital status from 6 to 26 months after random assignment. For example, if a mother reported she was living together, unmarried at wave 1 , indicated she was married at wave 2 , and separated at wave 3 , her value on this variable was 2 . 
Scores ranged from 0 (no changes) to 2 (a change at each time point). Participants who did not have marital status data for at least two of the three waves were marked "missing" for this variable $(N=19)$. If data were missing for one wave, data on the other two waves were compared. For instance, if data for wave 1 are missing, only wave 2 and wave 3 were assessed for change, as it would have been impossible to know if a change in status occurred from wave 1 to 2 . Similar coding schemes can be found in previous work examining environmental unpredictability (Belsky et al., 2012). Such a scheme provides a conservative estimate of marital transitions while maximizing the use of the available data. Five hundred sixty-eight mothers experienced no change in their marital status, 272 experienced one change in their marital status, and 107 mothers experienced two changes in their marital status.

Maternal employment transitions. Mothers provided employment information (0 $=$ not employed, $1=$ employed) each quarter (approximately every three months) from 6 to 26 months after random assignment. Maternal employment transitions was calculated as the number of changes (gains or losses) in maternal employment across the eight time points. Scores ranged from 0 (no changes) to 3 (three or more changes). Groups beyond 3 changes had too few families to stand alone in analyses $(N=9)$. The same coding scheme applied to maternal marital transitions (described above) was applied to maternal employment. If data were missing for the previous quarter but were available for a subsequent quarter, data from that quarter were compared to data from the most recent available time point. For example, if data from Quarter 2 were missing, employment status at Quarter 3 was compared to employment status at Quarter 1. The same coding scheme was applied to participants who had data missing for multiple quarters. For 
instance, if a participant had data from Quarter 1, Quarter 5, and Quarter 8 with all other quarters missing, employment status at Quarter 5 was compared to employment status at Quarter 1 and employment status at Quarter 8 was compared to employment status and Quarter 5. All participants had employment data for at least two of the eight waves. Three hundred eighty-nine mothers experienced no changes in employment, 326 mothers experienced one employment change, 157 mothers experienced two employment changes, and 94 mothers experienced three or more employment changes.

Residential mobility. Mothers indicated if they had ever moved by 26 months after random assignment $(1=$ yes; $0=$ no). Six hundred fifty-seven families moved at least once by 26 months after random assignment. Two hundred seventy-seven families had not moved by this time point. Thirty-two families had missing data on this variable.

Environmental harshness. As in other research (Belsky et al., 2012; Doom et al., 2016; Ellis et al., 2009; Simpson et al., 2012), environmental harshness was indexed by indicators related to SES. Three indicators, poverty status, average income-to-needs ratio, and average public assistance, were used to assess environmental harshness in the first three years of life. These measures were collected from 6 to 26 months after random assignment.

Poverty status. Poverty status was determined by EHSREP researchers. The poverty level cutoffs for each household were determined by household size and composition. Household income was then compared to the given poverty level to determine if the family fell above or below this threshold at 26 months after random assignment. A value of 0 indicated income less than the poverty line. A value of 1 indicated income above the poverty line. Five hundred eighteen families were living 
below the poverty line at 26 months after random assignment. Three hundred ninety families were living above the poverty line at this time point. Fifty-eight families were missing data on this variable.

Average income-to-needs ratio. Mother-reported monthly income, including total amount of money received by all members of the family, public assistance, and other government transfers, was reported for each month from focus children's birth through their third birthday. Monthly income was summed to create household income totals for child age ranges from 0 to 14 months, 14 to 24 months, and 24 to 36 months (see LugoGil \& Tamis-LeMonda, 2008, for a complete description).

These three totals were divided by the number of individuals in the household during the corresponding time frame to calculate three income-to-needs ratios for each family. These ratios were then averaged and standardized to create an index of average income-to-needs ratio for each family. Lower income-to-needs ratios indicate greater depth of poverty. Because income data for some families was missing, average incometo-needs was modeled as a proportional value based on the number of time frames for which there were data. For example, if families had income-to-needs data for 0 to 14 months and 14 to 24 months, but were missing income data for 24 to 36 months, the ratios for the first two intervals were summed and divided by two. Similar strategies have been adopted in other research using this data set (Mistry, Benner, Biesanz, Clark, \& Howes, 2010). Twenty-one families did not have income data at any of the 3 time points, and thus, have missing data on this variable.

Average public assistance. Mothers provided information about whether or not they received public assistance $(0=$ did not receive assistance, $1=$ received assistance $)$ 
each quarter (approximately every three months) from 6 to 26 months after random assignment. Values were averaged to create a single score for public assistance received. Higher scores indicated more public assistance received. Average public assistance was modeled as a proportional score, such that total receipt of public assistance was divided by the total number of quarters with data. Averages ranged from 0 to 1 . Four families did not have public assistance data at any of the time points, and thus, have missing data on this variable.

Maternal positive parenting practices. Maternal positive parenting was indexed by three indicators: maternal warmth, maternal supportiveness, and cognitive stimulation.

Maternal warmth. Maternal warmth was based on data obtained during home visits when children were approximately 36 months old. After these home visits, interviewers completed the HOME scale (Caldwell \& Bradley, 1984). Three items drawn from the 11-item responsivity scale of the HOME were used to assess maternal warmth in the current study. These items included: (a) parent's voice conveys positive feelings towards the child, (b) parent spontaneously praises child's qualities twice during visit, and (c) parent caresses, kisses, or cuddles child during visit. Scores on maternal warmth ranged from 0 (no positive behaviors were observed) to 3 (all positive behaviors were observed). Scores were standardized for purposes of analysis. One hundred forty-six families were missing data on this variable.

Maternal supportiveness. Maternal supportiveness was evaluated during a puzzle challenge task (Brady-Smith, Ryan, Berlin, Brooks-Gunn, \& Fuligni, 2001) completed by mothers and their children when children were approximately 36 months old. Four 
aspects of the mother's behavior with the child (emotional availability, physical and affective presence, provision of a secure base, and displaying emotional support and enthusiasm) were rated on a 7-point scale. Scores ranged from 1 (very low incidence of behaviors) to 7 (very high incidence of behaviors). The task was videotaped and subsequently coded by EHSREP researchers according to a developed protocol. Scores were standardized for use in the proposed study. One hundred ninety-four families were missing data on this variable.

Cognitive stimulation. Cognitive stimulation was assessed during a home visit when focus children were approximately 36 months old using the HOME Support of Language and Learning subscale (Caldwell \& Bradley, 1984). This 10-item subscale contains both self-report and observed items. Items assess the availability of toys and reading materials at home (e.g., child has access to at least 10 children's books), parentchild verbal interaction (e.g., parent usually responds verbally to child's speech), and parental encouragement of learning (e.g., child is encouraged to learn the alphabet). All items were coded dichotomously $(0=$ no, $1=$ yes $)$. Participants who did not have data for at least seven of the 10 items were marked "missing" for this variable $(N=128)$. For participants missing three or fewer items, each missing item was replaced by the item mean (Parent, 2013). Items were then summed and standardized to create a continuous measure of cognitive stimulation. Acceptable reliability for this subscale has been established with multiple samples, including low-income families (Totsika \& Sylva, 2004).

Preschool self-regulation. Ratings on the Attention, Activity Level, and Emotion Regulation subscales of the Leiter-R Examiner Rating Scales (Roid \& Miller, 1997) were 
used to assess attention, behavior, and emotion regulation, respectively. Assessments were conducted the spring prior to kindergarten entry. The Leiter-R consists of 49 examiner-rated items that focus on the actions, moods, verbalizations, and behaviors of children during a math and literacy skills assessment. Scores for each item ranged from 0 (rarely or never observed) to 3 (usually observed). Items are positively phrased such that higher ratings correspond with higher levels of self-regulation (e.g., "The subject stays on task, with minimal reinforcement"). The Leiter-R scales have been widely used in the assessment of preschool children (Tsatsanis et al., 2003). Studies using items from the three subscales noted above to assess self-regulation have demonstrated acceptable construct and concurrent validity (Smith-Donald, Raver, Hayes, \& Richardson, 2009). Raw scores for each scale were converted to scaled scores by application of age appropriate norms. Higher values on all scales indicated better regulation in the corresponding domain.

Attention regulation. Attention regulation was based on the attention subscale of the Leiter-R, which is composed of 10 items. Higher scores on this scale represent higher levels of attention and concentration (e.g., non-distractibility while completing difficult tasks). Six participants were missing data on this variable.

Behavior regulation. Behavior regulation was based on the activity level subscale of the Leiter-R, which is composed of four items. Higher scores on this scale represented appropriate levels of movement during the assessment (e.g., no excessive or repetitive movement, no fidgeting). No participants were missing data on this variable.

Emotion regulation. Emotion regulation was based on the emotion regulation subscale of the Leiter-R, which is composed of six items. Scores on this scale represent 
children's ability to regulate their emotions during a potentially taxing task. Higher scores indicated that the child demonstrated appropriate (not overly aroused, anxious, or irritable) emotions during the assessment. Ten participants were missing data on this variable.

Demographic information. Several demographic factors were included as controls in data analyses. Mothers' ethnicity (European American, $N=402$; African American, $N=316$; Hispanic, $N=215$ ) child gender (female, $N=430$; male, $N=445$ ), and program group (control, $N=464$; Early Head Start, $N=502$ ) were obtained from the program application and enrollment forms. 


\section{Chapter 4: Results}

Structural Equation Modeling (SEM) was conducted to examine the influence of early-life environmental unpredictability and environmental harshness on levels of selfregulation in preschool, and to test whether positive parenting mediates these effects. The conceptual model is presented in Figure 1. Descriptive statistics and bivariate relations are reported first. The results of the measurement model are then provided, followed by the results of the structural models. All models were tested with Mplus 7.4 (Muthen \& Muthen, 2010) using a robust weighted least squares approach (WLSMV estimation).

\section{Descriptive Statistics and Bivariate Relations}

Means, standard deviations, and proportion of missing data for each study variable are reported in Table 1. The proportion of missing data for the study variables ranged from $0 \%$ to $20 \%$. Most variables (two-thirds) had less than five percent missing data. Bivariate correlations between model variables are also reported in Table 1. As expected, indicators of environmental unpredictability - maternal marital transitions, maternal employment transitions, and residential mobility — were significantly positively correlated with one another. Also as expected, indicators of environmental harshnessaverage public assistance, average income-to-needs ratio, and poverty status-were significantly correlated with one another. Finally, the three indicators of positive parenting - maternal warmth, maternal supportiveness, and cognitive stimulation-were significantly positively correlated. These correlations provide some evidence of construct validity for the three latent variables included in the model depicted in Figure 1.

As shown in Table 1, ethnicity (dummy coded for use in bivariate analyses, $1=$ European American, $0=$ all else $)$ and child sex $(0=$ female, $1=$ male $)$ were related to 
several of the main study variables. Ethnicity was significantly related to income-toneeds ratios, poverty status, maternal marital transitions, maternal supportiveness, warmth, and cognitive stimulation, and children's behavior regulation. Mean level comparisons revealed that European American mothers had significantly higher incometo-needs ratios $(M=5210.22, S D=3140.87)$ compared to African American $(M=$ 3754.56, $S D=2968.97)$ and Hispanic $(M=1493.40, S D=1.13)$ mothers, $F=21.68, p<$ .001. The proportion of African Americans living below the poverty line (68.9\%) was significantly larger than the proportion of European Americans (49.7\%) and Hispanic Americans $(53.7 \%)$ living below poverty, $\chi^{2}(2, N=879)=26.26, p<.001$. European American mothers experienced significantly more marital transitions on average $(M=$ $.57, S D=.71)$ compared to African American mothers $(M=.40, S D=.66), F=5.45, p=$ .004. European American mothers demonstrated significantly higher supportiveness $(M=$ 4.92, $S D=1.20)$ than did African American $(M=4.18, S D=1.35)$ and Hispanic $(M=$ 4.30, $S D=1.29)$ mothers, $F=28.93, p<.001$. European American mothers also demonstrated higher cognitive stimulation $(M=9.04, S D=1.13)$ than did African American $(M=8.57, S D=1.50)$ and Hispanic $(M=8.47, S D=1.47)$ mothers, $F=14.71$, $p<.001$. African American mothers demonstrated significantly less warmth $(M=2.4, S D$ $=.94)$ compared to European American $(M=2.6, S D=.73)$ and Hispanic $(M=2.6, S D=$ $.80)$ mothers, $F=5.47, p=.004$. Despite the significant bivariate correlation, mean level comparisons for children's emotion regulation revealed no significant differences among ethnic groups, $F=1.99, p=.14$.

Child sex was correlated with income-to-needs ratios, maternal supportiveness, and cognitive stimulation, as well as attention, behavior, and emotion regulation. Girls 
lived in homes that had higher income-to-needs ratios $(M=4765.86, S D=3215.11)$ and were more cognitively stimulating $(M=8.87, S D=1.30)$ compared to boys $(M=$ 4210.47, $S D=2932.27 ; t(855)=2.64, p=.008$ and $M=8.64, S D=1.42 ; t(756)=2.32$, $p=.020$, respectively). Mothers of girls demonstrated significantly more supportiveness $(M=4.66, S D=1.23)$ than mothers of boys $(M=4.45, S D=1.33), t(697)=2.13, p=$ .034. Girls had significantly higher scores on attention $(M=9.10, S D=1.38)$, behavior $(M=8.83, S D=1.54)$, and emotion regulation $(M=8.81, S D=1.46)$ compared to boys $(M=8.19, S D=2.19 ; t(870)=7.30, p<.001, M=7.80, S D=2.34 ; t(873)=7.691, p<$ .001 , and $M=8.04, S D=2.10 ; t(863)=6.25, p<.001$, for attention, behavior, and emotion regulation, respectively). Given the significant relations among many of the main study variables, ethnicity, and child sex, multiple groups analyses for sex and ethnicity were conducted. Results of these analyses are presented below. Program group was not significantly related to any of the main study variables, and thus, will not be considered henceforth.

Correlations among indicators of environmental unpredictability, environmental harshness, and outcome variables are also presented in Table 1. Maternal marital and employment transitions were negatively associated with children's attention and emotion regulation. There were also significant correlations between income-to-needs ratios and receipt of public assistance and all domains of children's self-regulation. Lower incometo-needs ratios and more receipt of public assistance were associated with lower attention, behavior, and emotion regulation. Living below the poverty line was also associated with lower attention regulation. All three indicators of environmental harshness were related to aspects of positive parenting practices. Lower income-to-needs 
ratios, living below the poverty line, and receiving more public assistance were significantly associated with lower maternal warmth, supportiveness, and cognitive stimulation. The magnitude of most correlations were small- to moderate $(r s<.50)$.

\section{Confirmatory Factor Analysis}

A confirmatory factor analysis (CFA) was conducted to test the structure of the latent factors included in the model. Results of the CFA are presented in Figure 2. Maternal marital transitions, maternal employment transitions, and residential mobility were specified as indicators of the latent construct environmental unpredictability. Average income-to-needs ratio, average receipt of public assistance, and living above or below the poverty line were specified as indicators of the latent construct environmental harshness. Maternal warmth, maternal supportiveness, and cognitive stimulation were specified as indicators of the latent construct maternal positive parenting.

Factor loadings were freely estimated, and the latent variance of each latent factor was fixed to 1.0. Correlations among the latent factors were estimated. Fit indices, including chi-square, root-mean-square error of approximation (RMSEA), Tucker-Lewis index (TLI), and comparative fit index (CFI), were examined to verify model fit. In general, a non-significant chi-square, a RMSEA below .05, and a CFI and TLI greater than .90 reflect acceptable model fit (Hu \& Bentler, 1998; Schumacker \& Lomax, 2004). Fit indices indicated good model fit $\chi^{2}(24)=64.47, p<.001 ;$ TLI $=.96 ;$ CFI $=.97$; RMSEA $=.042,90 \%$ confidence interval (CI) $[.030, .054]$. The significant chi-square is not surprising given the sensitivity of the chi-square test statistic to large sample size. All other indices fell within acceptable ranges. 
As depicted in Figure 2, all factor loadings were significant and ranged from .25 to .93. Standardized path loadings for the indicators of environmental unpredictabilitymaternal marital transitions, maternal employment transitions, and residential mobilitywere $.29, .39$, and .25 , respectively. Standardized path loadings for the indicators of environmental harshness - average income-to-needs ratio, average receipt of public assistance, and living above or below the poverty line-were -.85, .56 , and -.93 , respectively. Standardized path loadings for the indicators of maternal positive parenting — warmth, supportiveness, and cognitive stimulation-were $.53, .60$, and .61, respectively. Environmental unpredictability and harshness were only moderately correlated $(r=.41)$.

\section{Structural Regression Model}

The structural regression model is depicted in Figure 3. The analysis model included three latent factors representing environmental harshness, environmental unpredictability, and positive parenting practices, as well as three observed variables: attention, behavior, and emotion regulation. Eleven direct paths were estimated: from environmental unpredictability to positive parenting practices (1) and attention (2), behavior (3), and emotion self-regulation (4); from environmental harshness to positive parenting practices (5) and attention (6), behavior (7), and emotion self-regulation (8); and from positive parenting practices to attention (9), behavior (10), and emotion selfregulation (11). Six indirect paths were estimated: from environmental unpredictability to the three measures of self-regulation via positive parenting practices $(1,2,3)$ and from environmental harshness to the three measures of self-regulation via positive parenting practices $(4,5,6)$. 
Model fit. The fit indices described above were evaluated to determine model fit. All indices fell within acceptable ranges, indicating an overall good fit of the model to the data: $\chi^{2}(42)=82.21, p<.001 ; \mathrm{TLI}=.97 ; \mathrm{CFI}=.98 ; \mathrm{RMSEA}=.031,90 \% \mathrm{CI}(.021$, .042). The significant chi-square is not surprising given the sensitivity of the chi-square statistic to large samples. All other indices fell within acceptable ranges.

Direct and indirect effects. To determine if exposure to environmental unpredictability and environmental harshness during the first three years of life directly and/or indirectly influenced aspects of cognitive, behavioral, and emotion regulation in preschool, the direct and indirect associations among environmental unpredictability and harshness, positive parenting, and child attention, emotion, and behavior regulation were tested. The direct effects are presented first, followed by the indirect effects.

As depicted in Figure 3, environmental unpredictability was inversely associated with emotion regulation. Children who experienced more unpredictability in the first three years of life had significantly lower emotion regulation in preschool. Environmental harshness was negatively related to positive parenting, indicating that greater environmental harshness from birth to 36 months was associated with less positive parenting when children were 36 months old. Together, environmental unpredictability and environmental harshness accounted for $17.4 \%$ of the variance in positive parenting. Positive parenting at 36 months was positively associated with attention and emotion regulation in preschool, such that more positive parenting was associated with better attention and emotion regulation.

To test whether positive parenting mediates the associations between environmental unpredictability and environmental harshness and children's attention, 
behavior, and emotion regulation, six indirect paths were tested. A significant indirect effect of environmental harshness on children's attention regulation through positive parenting practices was found, $\beta=-.182, S E=.056, p<.001$. Greater environmental harshness was associated with less positive parenting, which in turn was related to poorer attention regulation.

Multiple group analyses. To test for sex and ethnic differences in the model depicted in Figure 3, multiple group analyses for sex and ethnicity were conducted. Because no significant group differences were found between African American and Hispanic mothers on five of the seven main study variables associated with ethnicity, these two groups were combined into one group for use in the multiple group analysis. Indicators of the latent constructs were constrained to be equal across groups to establish measurement invariance (Kline, 2015). Regression coefficients were first freely estimated (alternative model), then constrained across groups (null model). As depicted in Table 2, constraining the structural paths to be equal across boys and girls and across European Americans and African Americans and Hispanic Americans significantly worsened model fit, indicating that the model depicted in Figure 3 significantly varies by child sex and by ethnicity.

The model for boys is presented in Figure 4, and the model for girls is presented in Figure 5. As shown in Figure 4, environmental unpredictability was inversely directly associated with emotion regulation among boys. Boys who experienced greater environmental unpredictability during the first three years of life demonstrated significantly lower emotion regulation in preschool. By contrast, environmental 
unpredictability was not significantly directly or indirectly associated with girls' selfregulation, as shown in Figure 5.

For boys, environmental harshness was significantly indirectly related to attention regulation. More environmental harshness from age 0 to 36 months was associated with less positive parenting at 36 months, which in turn was associated with lower attention regulation among boys during preschool, $\beta=-.138, S E=.057, p=.015$. Although greater environmental harshness was significantly inversely associated with positive parenting practices for girls, positive parenting practices was not associated with any of the three components of self-regulation among girls.

The model for European Americans is presented in Figure 6, and the model for African Americans and Hispanic Americans (combined) is presented in Figure 7. For both groups, environmental harshness from birth to 36 months was inversely associated with positive parenting at 36 months, indicating that, regardless of ethnicity, greater environmental harshness is related with less positive parenting. In addition, less positive parenting at 36 months was associated with lower attention regulation at preschool entry for both groups. Among the European American group, less positive parenting was also associated with lower emotion regulation. This association was not significant for the African American and Hispanic American group. 


\section{Chapter 5: Discussion}

The purpose of the current study was to examine the unique direct and indirect effects of early-life environmental unpredictability and environmental harshness on preschoolers' self-regulation. To accomplish this objective, multi-method multiinformant longitudinal data from the EHSREP were used to separate the influences of harsh and unpredictable environments on children's self-regulation and examine positive parenting practices as a mediator of these associations. While the correlational nature of these data does not allow for casual conclusions, results indicate that early-life environmental unpredictability and environmental harshness make independent and unique contributions to preschoolers' self-regulation. Findings also suggest that the effects of environmental unpredictability, environmental harshness, and parenting practices on children's self-regulation are domain specific and may not operate equally across all groups of children.

\section{Environmental Unpredictability and Environmental Harshness as Independent}

\section{Predictors of Self-Regulation}

Environmental unpredictability and environmental harshness were conceptualized as distinct dimensions of environmental risk (see Ellis et al., 2009). Environmental unpredictability was represented by changes in maternal employment and marital status and residential mobility when children were between the ages of 0 to 3 years. Environmental harshness was represented by average income-to-needs ratios, poverty status, and receipt of public assistance when children were between the ages of 0 to 3 years. I hypothesized that as distinct dimensions of risk, environmental unpredictability and environmental harshness would independently contribute to variation in preschool 
children's self-regulation. This hypothesis was supported. Not only did environmental unpredictability and environmental harshness independently contribute to variation in children's self-regulation, but each did so uniquely — through different pathways to different domains of self-regulation. Early-life environmental unpredictability was directly and negatively associated with preschoolers' emotion regulation. Early-life environmental harshness was indirectly and negatively associated with preschoolers' attention regulation. These unique patterns of associations varied across boys and girls, and to a smaller extent, across ethnic groups. The direct effect of environmental unpredictability on children's emotion regulation is discussed first, followed by the indirect effect of environmental harshness on children's attention regulation. Variation in these associations by child sex and ethnic group is highlighted throughout. Finally, the domain specificity of these effects is discussed.

Environmental unpredictability. As depicted in Figure 3, greater environmental unpredictability encountered during the first three years of children's lives was associated with poorer emotion regulation during preschool. This association was independent of both environmental harshness and positive parenting, suggesting that environmental unpredictability early in life has a direct and negative impact on preschooler's selfregulation beyond the influence of consistently low economic resources and supportive, warm, and stimulating caregiving. This finding is consistent with previous studies that have reported negative associations between aspects of environmental unpredictability (e.g., residential mobility, Schmitt, Finders, \& McClelland, 2015; household instability, McCoy \& Raver, 2014) and children's self-regulation and provides further evidence of environmental unpredictability as a distinct and important aspect of environmental risk 
within economically-disadvantaged families. Exposure to environmental unpredictability early in life may place children on a developmental trajectory towards poor selfregulation by the time they reach preschool.

This finding may also help clarify some of the inconsistent conclusions in the literature about the extent and direction environmental unpredictability correlates with children's self-regulation. As noted in the introduction, some studies (e.g., McCoy \& Raver, 2014; Lengua, Honorado, \& Bush, 2007; Schmitt et al., 2015) have found support for a negative relation between aspects of environmental unpredictability and components of children's regulatory abilities, while other studies (e.g., Vernon-Feagans et al., 2016) have found no association between the two constructs. Both McCoy and Raver (2014) and Lengua et al. (2007) reported significant relations between aspects environmental unpredictability and components of children's emotion regulation, and McCoy and Raver (2014) reported no significant relations between household instability and measures of children's cognitive self-regulation. Vernon-Feagans et al. (2016) reported no significant relations between household instability and children's behavioral self-regulation. These findings are all consistent with those reported in the present study.

Together, these seemingly inconsistent findings reported in the literature may, in part, be related to the domain of self-regulation assessed by researchers. It appears that preschoolers' emotion regulation may be especially vulnerable to the influence of environmental unpredictability, while preschoolers' cognitive and behavioral regulation may not. Environmental unpredictability may disrupt children's sense of emotional security and control over their immediate environments which, in turn, may compromise their ability to develop more effective emotion regulation strategies (Ackerman, Kogos, 
Youngstrom, Schoff, \& Izard, 1999; Cummings \& Davies, 1996; Garrett-Peters et al., 2016; see Raver, Blair, \& Garrett-Peters, 2015 for an exception).

Contrary to expectations, the present study did not find evidence that positive parenting mediates the association between early-life environmental unpredictability and preschoolers' self-regulation. This effect may truly be direct and unmediated, as depicted in Figure 3. As noted in the introduction, unpredictable environmental contexts tend to facilitate the adoption of an unpredictability schema (Cabeza de Baca et al., 2016) and present time orientation, which encourage the development of impulsive and reactive behaviors in order to capture immediate rewards and capitalize on opportunities that are likely to be short-lived (Ellis et al., 2009; Frankenhuis et al., 2016; McGuire \& Kable, 2013). Indeed, researchers have concluded that even in the presence of acute unpredictability, children's self-regulatory skills diminish, perhaps to match their views about the stability of the environment and the cost/benefit of delaying gratification.

For instance, in a laboratory environment designed to be reliable or unreliable, Kidd, Palmeri, and Aslin (2013) reported that children in a reliable condition (i.e., the researcher demonstrated his/her reliability by returning with art materials as promised prior to the task) delayed gratification for significantly longer periods of time on the marshmallow task compared to children in an unreliable condition (i.e., the researcher did not return with the art materials as promised). These results support the notion that young children are sensitive to environmental unpredictability and that a view of the world as unreliable has the potential to shape children's regulatory behaviors (Kidd, Palmeri, \& Aslin, 2013). 
While it is conceivable that the effect of early-life unpredictability on preschool self-regulation is truly direct, it is also possible that no mediation was found in the present study for methodological reasons. First, it is possible the association between environmental unpredictability and self-regulation is mediated by other, unmeasured family- and child-level factors. One possible factor might be children's sense of mastery. Environments that are unpredictable may lack the kinds of structured, predictable, and sustained exchanges with caregivers that are important for children to develop a strong sense of mastery (Evans et al., 2005). A poor sense of mastery can undermine children's intrinsically motivated movement toward autonomous self-regulation (Grolnick, Kurowski, \& Gurland, 1999). Future research might be designed to explore other mediational processes that may account for how exposure to unpredictable environments early in life impacts the development of self-regulation.

It is also possible that no evidence for mediation was found due to measurement limitations of some of the study variables. For instance, although the definition and operationalization of environmental unpredictability in the present study is consistent with theory (Ellis et al., 2009) and research (e.g., Belsky et al., 2012), it does not capture the quality of the transitions (e.g., residential moves into and out of poverty) nor does it capture unpredictability across a wide array of possible transitional contexts that may impact positive parenting, such as maternal or child health. It is not clear if grouping transitions that can be perceived as positive (e.g., job attainment), which might increase positive parenting, with transitions that may be perceived as negative (e.g., job loss), which might disrupt positive parenting, made it difficult to find an association between environmental unpredictability and parenting practice in the present study. It is also not 
clear if frequent changes in other contexts outside of those included in the current measurement may have a greater effect on parenting. Future research exploring environmental unpredictability in other contexts and the quality of transitions that occur within those contexts may reveal additional associations among environmental unpredictability, parenting practices, and children's self-regulation that were not uncovered in the present study.

Although the present study found that children who experienced high levels of environmental unpredictability had poorer emotion regulation, follow-up multigroup analyses reveal that this association varies across boys and girls. As depicted in Figures 4 and 5, the relation between environmental unpredictability and emotion regulation was only significant for boys, indicating that boys may be more susceptible to the adverse effects of environmental unpredictability than girls. This finding is consistent with theory (differential susceptibility theory; Belsky, Bakermans-Kranenburg, \& van IJzendoorn, 2007) and research (e.g., Belsky, Hsieh, \& Crnic, 1998; Blair, 2002) that suggests some children are more influenced by their rearing experiences than others. Indeed, several researchers have concluded that boys are especially sensitive to adversity, including aspects of environmental unpredictability (e.g., Ackerman et al., 1999; Capaldi \& Patterson, 1991; Cavanagh \& Huston, 2008).

It is possible that exposure to unpredictable environments between the ages of 0 to 36 months is associated with later self-regulation during preschool among boys but not girls because boys have been found to be more temperamentally stress reactive than girls (Cavanagh \& Huston, 2008; Cummings, Davies, \& Simpson, 1994; Verma, Balhara, \& Gupta, 2011). Highly stress reactive children have been found to be more vulnerable in 
adverse environments than are children who are less reactive (Ackerman et al., 1999). Less reactive children may be able to easily adapt in unpredictable, constantly changing environments, while highly reactive children may have greater difficulty adjusting to frequent changes and thus, respond less favorably in unpredictable contexts (Ackerman at al., 1999). In unpredictable environments, boys may be more likely to experience higher levels of stress than girls, which might disrupt the development of neural systems important for self-regulation (e.g., PFC; Holmes \& Wellman, 2009) and core components of self-regulation that form the foundations on which later regulatory abilities are built (Bronson, 2000).

Environmental harshness. As shown in Figure 3, early-life environmental harshness diminished parents' warm, supportive, and stimulating interactions with their children at 36 months, which in turn impaired children's attention regulation during preschool. This finding is consistent with theory (e.g., Bronfenbrenner \& Morris, 2006) and research (e.g., Linver et al., 2002) that has emphasized more proximal family-level mechanisms as mediators of the relation between environmental harshness and children's self-regulation. While the associations among environmental harshness, parenting, and children's self-regulation are well established, the present study extends the understanding of these relations by demonstrating that exposure to harsh environments early in life indirectly influences later self-regulation beyond the effects of the frequent, rapid, and/or random changes that often characterize these environments. The present study also demonstrates that these effects are unique, following a different pathway and affecting a different domain of self-regulation than environmental unpredictability. The unique effects of environmental harshness found in the present study might indicate that 
harsh environments are distinct contexts of development in which children's regulatory abilities can be compromised.

As depicted in Figures 4 through 7, follow-up multiple group analyses revealed that the indirect effect of environmental harshness on attention regulation via positive parenting was only significant for boys and that there were no significant indirect effects for either ethnicity group. Although environmental harshness was significantly and negatively associated with positive parenting, positive parenting was not in turn associated with attention regulation among girls. This finding offers additional support to the theory and research mentioned above that suggests some children are more sensitive to rearing environments than others (e.g., Belsky et al., 2007) and is consistent with research that has indicated boys are more vulnerable to the effects of harsh parenting practices than are girls (e.g., Fay-Stammbach et al., 2014).

For instance, Mileva-Seitz and colleagues (2015) concluded that lower parental sensitivity at 36 months was significantly associated with poorer attention (assessed via a computerized Go/NoGo task; Mahone, Pillion, \& Hiemenz, 2001) in preschool boys but not girls. Interestingly, as in the present study, this effect was specific to attention. Lower parental sensitivity did not interact with other domains of boys' cognitive function (i.e., short-term and working memory). It is possible that sensitive parenting may serve as a calming buffer for boys in harsh environments, helping to reduce overstimulation and overactivity by creating a less chaotic environment in which boys are better able to develop effective attention regulation strategies (Mileva-Seitz et al., 2015).

One reason the effects of parenting on boys' self-regulation may differ from the effects of parenting on girls' regulation might be because boys may require more co- 
regulation (i.e., warm and responsive interactions that involve instruction, coaching, and support to promote children's regulatory development; Bronson, 2000) from their mothers than girls (Tronick \& Reck, 2009). If boys do require more co-regulation, their self-regulation may be more affected by harsher, less positive parenting (Mileva-Seitz et al., 2015).

Although the indirect effect of environmental harshness on preschoolers' attention regulation does not remain significant in multiple group analyses by ethnicity (likely because this effect is driven by boys), one interesting difference between the European American group and the Hispanic and African American group is the magnitude of the direct effect of positive parenting on attention and emotion regulation. As depicted in Figures 6 and 7, the effect of positive parenting on preschoolers' attention and emotion regulation is stronger for the European American group than for the Hispanic and African American group. This finding is consistent with other research suggesting that negative parenting is associated less proximally with regulatory skills in African American children than in White children (Rhoades, Greenberg, Lanza, \& Blair, 2011). Harsh environments seem to impair mothers' ability to interact with their children in warm, supportive, and stimulating ways, regardless of ethnicity. European American children in the current, however, seemed to be more vulnerable to the effects of harsh parenting than did Hispanic and African American children.

Domain specific effects. The present study found evidence for domain specific effects of environmental unpredictability and environmental harshness on self-regulation. Environmental unpredictability was directly related to preschoolers' emotion regulation but not their behavior or attention regulation, and environmental harshness was indirectly 
related to attention regulation, but not behavior or emotion regulation. These results are similar to those reported by McCoy and Raver (2014), who concluded that household instability was negatively associated with components of children's emotion regulation but not components of children's cognitive self-regulation. While it is possible that these findings truly reflect domain specific effects, it is also possible that the specific associations reported in the present study represent a global, domain general issue with self-regulation that is expressed in specific and variable ways as children develop.

For example, researchers examining family instability and children's problem behaviors suggest that children's general distress may be expressed in variable ways over time (e.g., externalizing for preschoolers, internalizing for first grades; Ackerman et al., 1999). Extending this conclusion to the present study, it is possible that environmental unpredictability and environmental harshness impair self-regulation generally, but that this impairment is expressed in specific ways based on contextual and developmental demands. The effects of environmental unpredictability and environmental harshness on children's self-regulation, thus, may be expressed differently among children of different ages and, perhaps, among children in different contexts (e.g., in a laboratory setting vs. in a classroom). Either possibility (i.e., domain specific or domain general effects) highlights the importance of unpacking self-regulation into specific domains in an effort to develop a more refined understanding of how adversity shapes the development of self-regulation. Future research might explore these possibilities by examining the effects of environmental unpredictability and environmental harshness on self-regulation across time and contexts. 


\section{Limitations, Implications, and Conclusions}

Although the EHSREP offers many advantages to researchers, including access to multi-method, multi-informant, and longitudinal data, the use of a preexisting data set in the present study placed constraints on how certain study constructs could be operationalized. For example, the measures of attention, behavior, and emotion regulation were drawn from examiner-rated items that focused on children's actions, moods, verbalizations, and behaviors during a math and literacy skills assessment. Although construct and concurrent validity of these measures has been established in other studies using these items to measure children's self-regulation (e.g., Smith-Donald et al., 2009), the items on the attention and activity subscale of the Leiter-R were not originally designed to assess self-regulation in these domains. Research designed to replicate the present findings with measures designed specifically to assess domains of self-regulation should be conducted.

Next, the exclusion criteria used in the present study resulted in a sample with significantly fewer African American and Hispanic American children compared to the sample of children who were excluded based on age and data availability. It is possible that this may limit the generalizability of these findings to more diverse samples. It is important to note however, that the sample used in the present sample was still highly diverse. Fifty-five percent of the children in the present sample were children of mothers who identified either as Hispanic or African American.

Despite these limitations, the findings of the present study add to the literature on environmental risk and children's self-regulation by examining the independent and unique contributions of environmental unpredictability and environmental harshness on 
preschoolers' attention, behavior, and emotion regulation. The present study found that environmental unpredictability and environmental harshness seem to be two contexts of development that convey independent and unique effects on the development of selfregulation among children from economically-disadvantage backgrounds. The results of the present study also indicate that the effects of environmental unpredictability and environmental harshness are not the same for all groups children.

As with any observational study, the correlational nature of these data does not permit strong interpretations or conclusions. With this in mind, one of the most promising implications of the findings from the present study is that there appears to be multiple ways to improve the self-regulation of children growing up in adverse contexts. For instance, children's self-regulation may benefit from efforts to improve economic resources (e.g., providing more public assistance) as well as efforts to reduce frequent, rapid, and/or random changes in children's environments (e.g., providing long-term housing assistance). Because environmental unpredictability and environmental harshness independently and differentially affect self-regulation, improvements in each should additively, not redundantly, contribute to increases in children's regulatory skills (Belsky et al., 2012). In harsh environments, efforts to improve children's self-regulation might also be aimed at increasing warm, supportive, and stimulating parent-child interactions.

Of course, the domains of self-regulation themselves might also be a point of consideration. Self-regulation is open to environmental influence and studies have found evidence that direct practice with regulatory skills, including working memory and inhibitory control, improves performance (Bierman \& Torres, 2016). For example, 
Klingberg, Forssberg, and Westerberg (2002) concluded that working memory training, which involved graduated practice on a set of working memory tasks, lead to significant increases in performance on an untrained working memory task. Improvements also generalized to tasks assessing other regulatory skills (e.g., attention inhibition). Although not conclusive, results of direct-training studies generally indicate that the direct training of self-regulatory abilities can promote acquisitions of these skills (e.g., Holmes, Gathercole, \& Dunning, 2009; Klingberg, Forssber, \& Westerberg, 2002).

It is important, however, not to assume that improving self-regulation is inherently preferable or that that poor self-regulation is by default maladaptive. Recall that from an evolutionary perspective, children learn about their world and adapt accordingly (Frakenhuis et al., 2015). Central to this perspective is the belief that adversity does not disrupt children's development, but rather directs development towards behaviors that are adaptive in adverse contexts, even if these behaviors could be harmful to the individual or society over time (Belsky et al., 2012). For instance, because future rewards are much less certain in unpredictable environments, behaviors designed to maximize fitness in unpredictable environments are likely to involve high levels of impulsivity and risk taking. Strong regulatory skills (e.g., inhibition) can be costly in quickly changing, unpredictable environments because they could prevent children from taking advantage of important, but fleeting, opportunities and rewards (Mittal et al., 2015). While much more research is needed before one can draw concrete implications about intervention and practice, it is important to consider the broader contexts in which children are situated when determining the appropriate steps to improve the wellbeing of children and families from economically-disadvantaged backgrounds. 
Although investigating group differences was not a primary goal of the present study, results of follow-up multigroup analyses suggest that relations between environmental unpredictability, environmental unpredictability, parenting practices, and children's self-regulation are unlikely to be the same for all children. Boys seem to be especially vulnerable to the effects of environmental unpredictability and environmental harshness. From a policy and practice perspective, understanding variations in vulnerability to environmental risk is important for developing effective ways to improve the lives of children and families facing adversity. The present study is an important first step in understanding the ways in which the influences environmental unpredictability, environmental harshness, and positive parenting on children's self-regulation simultaneously operate differently across children. These key dimensions of environmental risk likely interact with multiple individual, family, and community systems to affect children's self-regulation (Letourneau, Duffett-Leger, Levac, Watson, \& Young-Morris, 2011). A next step for future research is to investigate these interactions and examine how other systems may affect children's vulnerability.

Taken together, the findings of the present study lend support to the theoretical and empirical work that distinguishes environmental unpredictability and environmental harshness as two distinct dimensions of environmental risk (e.g., Belsky et al., 2012; Ellis et al., 2009; Simpson et al., 2012). These findings extend this work to the study of young children's self-regulation, highlighting the direct and indirect influences of both harsh and unpredictable environments on preschool children's attention, emotion, and behavior regulation. By disentangling the effects of environments that are harsh from the effects of environments that are unpredictable, the present study provides a more refined 
understanding of the ways in which specific aspects of environmental risk shape specific domains of self-regulation for specific groups of children. 


\section{References}

Ackerman, B. P., Kogos, J., Youngstrom, E., Schoff, K., \& Izard, C. (1999). Family instability and the problem behaviors of children from economically disadvantaged families. Developmental Psychology, 35(1), 258-268.

Beck, A. N., Cooper, C. E., McLanahan, S., \& Brooks-Gunn, J. (2010). Partnership transitions and maternal parenting. Journal of Marriage and Family, 72(2), 219233.

Belsky, J., Bakermans-Kranenburg, M. J., \& Van IJzendoorn, M. H. (2007). For better and for worse: Differential susceptibility to environmental influences. Current Directions in Psychological Science, 16(6), 300-304.

Belsky, J., Hsieh, K. H., \& Crnic, K. (1998). Mothering, fathering, and infant negativity as antecedents of boys' externalizing problems and inhibition at age 3 years: Differential susceptibility to rearing experience?. Development and Psychopathology, 10(02), 301-319.

Belsky, J., Schlomer, G. L., \& Ellis, B. J. (2012). Beyond cumulative risk: distinguishing harshness and unpredictability as determinants of parenting and early life history strategy. Developmental Psychology, 48(3), 662.

Bernier, A., Carlson, S. M., \& Whipple, N. (2010). From external regulation to selfregulation: Early parenting precursors of young children's executive functioning. Child Development, 81(1), 326-339.

Bierman, K. L., \& Torres, M. (2016). Promoting the development of executive functions through early education and prevention programs. Executive function in preschool 
age children: Integrating measurement, neurodevelopment and translational research. Washington, DC: American Psychological Association, 10, 14797-014.

Blair, C., \& Raver, C. C. (2012). Child development in the context of adversity: experiential canalization of brain and behavior. American Psychologist, 67(4), 309-318.

Blair, C., \& Razza, R. P. (2007). Relating effortful control, executive function, and false belief understanding to emerging math and literacy ability in kindergarten. Child Development, 78(2), 647-663.

Blair, C. (2010). Stress and the development of self-regulation in context. Child Development Perspectives, 4, 181-188.

Blair, C., Granger, D. A., Willoughby, M., Mills-Koonce, R., Cox, M., Greenberg, M. T., ... \& Fortunato, C. K. (2011). Salivary cortisol mediates effects of poverty and parenting on executive functions in early childhood. Child Development, 82(6), 1970-1984.

Blair, C., Raver, C. C., \& Berry, D. J. (2014). Two approaches to estimating the effect of parenting on the development of executive function in early childhood. Developmental Psychology, 50(2), 554-565.

Bradley, R. H., \& Corwyn, R. F. (2002). Socioeconomic status and child development. Annual Review of Psychology, 53(1), 371-399.

Brady-Smith, C., Ryan, R. M., Berlin, L. J., Brooks-Gunn, J., \& Fuligni, A. S. (2001). 36-month child-parent interaction rating scales for the puzzle task assessment. New York: Early Head Start Research and Evaluation Project, Center for Children and Families, Teachers College, Columbia University. 
Bronfenbrenner, U., \& Morris, P. A. (2006). The bioecological model of human development. In R.M. Lerner (Ed.) Handbook of child development: Vol. 1. Theoretical models of human development (6 ${ }^{\text {th }}$ ed., pp. 793-828). Hoboken, NJ: Wiley.

Bronson, M. (2000). Self-regulation in early childhood: Nature and nurture. New York: Guilford Press.

Brooks-Gunn, J., Klebanov, P. K., Smith, J., Duncan, G. J., \& Lee, K. (2003). The BlackWhite test score gap in young children: Contributions of test and family characteristics. Applied Developmental Science, 7(4), 239-252.

Cabeza de Baca, T., Barnett, M. A., \& Ellis, B. J. (2016). The development of the child unpredictability schema: Regulation through maternal life history trade-offs. Evolutionary Behavioral Sciences, 10(1), 43-55.

Caldwell, B. M., \& Bradley, R. H. (1984). Home observation for measurement of the environment. Little Rock: University of Arkansas at Little Rock.

Capaldi, D. M., \& Patterson, G. R. (1991). Relation of parental transitions to boys' adjustment problems: I. A linear hypothesis. II. Mothers at risk for transitions and unskilled parenting. Developmental Psychology, 27(3), 489-504.

Carlson, S. M. (2009). Social origins of executive function development. New Directions for Child and Adolescent Development, 2009(123), 87-98.

Cavanagh, S. E., \& Huston, A. C. (2008). The timing of family instability and children's social development. Journal of Marriage and Family, 70(5), 1258-1270.

Chazan-Cohen, R., Raikes, H., Brooks-Gunn, J., Ayoub, C., Pan, B. A., Kisker, E. E., ... \& Fuligni, A. S. (2009). Low-income children's school readiness: Parent 
contributions over the first five years. Early Education and Development, 20(6), 958-977.

Choe, D. E., Olson, S. L., \& Sameroff, A. J. (2013). Effects of early maternal distress and parenting on the development of children's self-regulation and externalizing behavior. Development and Psychopathology, 25(02), 437-453.

Conger, R. D., \& Donnellan, M. B. (2007). An interactionist perspective on the socioeconomic context of human development. Annu. Rev. Psychol., 58(1), 175199.

Cummings, E. M., \& Davies, P. (1996). Emotional security as a regulatory process in normal development and the development of psychopathology. Development and Psychopathology, 8(01), 123-139.

Cummings, E. M., Davies, P. T., \& Simpson, K. S. (1994). Marital conflict, gender, and children's appraisals and coping efficacy as mediators of child adjustment. Journal of Family Psychology, 8(2), 141-149.

Dalaker, J. (2001). Poverty in the United States: 2000 (US Census Bureau, Current Population Reports, Series P60-214). Washington, DC: US Government Printing Office.

Daly, M., \& Wilson, M. (2005). Carpe diem: Adaptation and devaluing the future. The Quarterly Review of Biology, 80(1), 55-60.

de Ridder, D. T., Lensvelt-Mulders, G., Finkenauer, C., Stok, F. M., \& Baumeister, R. F. (2012). Taking stock of self-control: A meta-analysis of how trait self-control relates to a wide range of behaviors. Personality and Social Psychology Review, 16(1), 76-99. 
Diamond, D. M., Campbell, A. M., Park, C. R., Halonen, J., \& Zoladz, P. R. (2007). The temporal dynamics model of emotional memory processing: a synthesis on the neurobiological basis of stress-induced amnesia, flashbulb and traumatic memories, and the Yerkes-Dodson law. Neural Plasticity, 2007, 1-33.

Doom, J. R., Vanzomeren-Dohm, A. A., \& Simpson, J. A. (2016). Early unpredictability predicts increased adolescent externalizing behaviors and substance use: A life history perspective. Development and Psychopathology, 28(4), 1-12.

Ellis, B. J., Figueredo, A. J., Brumbach, B. H., \& Schlomer, G. L. (2009). Fundamental dimensions of environmental risk. Human Nature, 20(2), 204-268.

Evans, G. W., \& English, K. (2002). The environment of poverty: Multiple stressor exposure, psychophysiological stress, and socioemotional adjustment. Child Development, 73(4), 1238-1248.

Evans, G. W., \& Kim, P. (2013). Childhood poverty, chronic stress, self-regulation, and coping. Child Development Perspectives, 7(1), 43-48.

Evans, G. W. (2004). The environment of childhood poverty. American Psychologist, 59(2), 77-92.

Evans, G. W., Boxhill, L., \& Pinkava, M. (2008). Poverty and maternal responsiveness: The role of maternal stress and social resources. International Journal of Behavioral Development, 32(3), 232-237.

Evans, G. W., Gonnella, C., Marcynyszyn, L. A., Gentile, L., \& Salpekar, N. (2005). The role of chaos in poverty and children's socioemotional adjustment. Psychological Science, 16(7), 560-565. 
Fawcett, T. W., McNamara, J. M., \& Houston, A. I. (2012). When is it adaptive to be patient? A general framework for evaluating delayed rewards. Behavioural Processes, 89(2), 128-136.

Fay-Stammbach, T., Hawes, D. J., \& Meredith, P. (2014). Parenting influences on executive function in early childhood: A review. Child Development Perspectives, $8(4), 258-264$.

Feagans, L., \& Farran, D. C. (1981). How demonstrated comprehension can get muddled in production. Developmental Psychology, 17(6), 718-727.

Feagans, L., \& Short, E. J. (1986). Referential communication and reading performance in learning disabled children over a 3-year period. Developmental Psychology, 22(2), 177-183.

Feldman, R., \& Klein, P. S. (2003). Toddlers' self-regulated compliance to mothers, caregivers, and fathers: implications for theories of socialization. Developmental Psychology, 39(4), 680-692.

Frankenhuis, W. E., Panchanathan, K., \& Nettle, D. (2016). Cognition in harsh and unpredictable environments. Current Opinion in Psychology, 7, 76-80.

Fuligni, A. S., Han, W. J., \& Brooks-Gunn, J. (2004). The infant-toddler HOME in the 2nd and 3rd years of life. Parenting, 4(2-3), 139-159.

Garrett-Peters, P. T., Mokrova, I., Vernon-Feagans, L., Willoughby, M., Pan, Y., \& Family Life Project Key Investigators. (2016). The role of household chaos in understanding relations between early poverty and children's academic achievement. Early Childhood Research Quarterly, 37, 16-25. 
Gerstadt, C. L., Hong, Y. J., \& Diamond, A. (1994). The relationship between cognition and action: performance of children $312-7$ years old on a stroop-like day-night test. Cognition, 53(2), 129-153.

Graziano, P. A., Calkins, S. D., \& Keane, S. P. (2010). Toddler self-regulation skills predict risk for pediatric obesity. International Journal of Obesity, 34(4), 633641.

Griskevicius, V., Tybur, J. M., Delton, A. W., \& Robertson, T. E. (2011). The influence of mortality and socioeconomic status on risk and delayed rewards: a life history theory approach. Journal of Personality and Social Psychology, 100(6), 10151026.

Grolnick, W. S., \& Kurowski, C. O. (1999). Family processes and the development of children's self-regulation. Educational Psychologist, 34(1), 3-14.

Hackman, D. A., \& Farah, M. J. (2009). Socioeconomic status and the developing brain. Trends in Cognitive Sciences, 13(2), 65-73.

Hart, B., \& Risley, T. R. (1995). Meaningful differences in the everyday experience of young American children. Baltimore, MD: Brookes.

Hoff, E., Laursen, B., \& Tardif, T. (2002). Socioeconomic status and parenting. In M.H. Bornstein (Ed.), Handbook of parenting (2 ${ }^{\text {nd }}$ ed., pp. 231-252). Mahwah, NJ: Erlbaum.

Holmes, J., Gathercole, S. E., \& Dunning, D. L. (2009). Adaptive training leads to sustained enhancement of poor working memory in children. Developmental Science, 12(4), 9-15. 
Holmes, A., \& Wellman, C. L. (2009). Stress-induced prefrontal reorganization and executive dysfunction in rodents. Neuroscience \& Biobehavioral Reviews, 33(6), $773-783$.

Hu, L. T., \& Bentler, P. M. (1998). Fit indices in covariance structure modeling: Sensitivity to underparameterized model misspecification. Psychological Methods, 3(4), 424-453.

Kidd, C., Palmeri, H., \& Aslin, R. N. (2013). Rational snacking: Young children's decision-making on the marshmallow task is moderated by beliefs about environmental reliability. Cognition, 126(1), 109-114.

Kline, R. B. (2015). Principles and practice of structural equation modeling. New York: Guilford publications.

Klingberg, T., Forssberg, H., \& Westerberg, H. (2002). Training of working memory in children with ADHD. Journal of Clinical and Experimental Neuropsychology, 24(6), 781-791.

Kochanska, G., Murray, K. T., \& Harlan, E. T. (2000). Effortful control in early childhood: continuity and change, antecedents, and implications for social development. Developmental Psychology, 36(2), 220-232.

Lengua, L. J., Honorado, E., \& Bush, N. R. (2007). Contextual risk and parenting as predictors of effortful control and social competence in preschool children. Journal of Applied Developmental Psychology, 28(1), 40-55.

Lengua, L. J., Kiff, C., Moran, L., Zalewski, M., Thompson, S., Cortes, R., \& Ruberry, E. (2014). Parenting mediates the effects of income and cumulative risk on the development of effortful control. Social Development, 23(3), 631-649. 
Letourneau, N. L., Duffett-Leger, L., Levac, L., Watson, B., \& Young-Morris, C. (2013). Socioeconomic status and child development: A meta-analysis. Journal of Emotional and Behavioral Disorders, 21(3), 211-224.

Linver, M. R., Brooks-Gunn, J., \& Kohen, D. E. (2002). Family processes as pathways from income to young children's development. Developmental Psychology, 38(5), $719-734$.

Lugo-Gil, J., \& Tamis-LeMonda, C. S. (2008). Family resources and parenting quality: Links to children's cognitive development across the first 3 years. Child Development, 79(4), 1065-1085.

Maholmes, V., \& King, R. B. (2012). The Oxford handbook of poverty and child development. New York, NY: Oxford University Press.

Mahone, E. M., Pillion, J. P., \& Hiemenz, J. R. (2001). Initial development of an auditory continuous performance test for preschoolers. Journal of Attention Disorders, 5(2), 93-106.

McCoy, D. C., \& Raver, C. C. (2014). Household instability and self-regulation among poor children. Journal of Children and Poverty, 20(2), 131-152.

McGuire, J. T., \& Kable, J. W. (2013). Rational temporal predictions can underlie apparent failures to delay gratification. Psychological Review, 120(2), 395-410.

McLoyd, V. C., Jayaratne, T. E., Ceballo, R., \& Borquez, J. (1994). Unemployment and work interruption among African American single mothers: Effects on parenting and adolescent socioemotional functioning. Child Development, 65(2), 562-589.

Mileva-Seitz, V. R., Ghassabian, A., Bakermans-Kranenburg, M. J., van den Brink, J. D., Linting, M., Jaddoe, V. W., ... \& van IJzendoorn, M. H. (2015). Are boys more 
sensitive to sensitivity? Parenting and executive function in preschoolers. Journal of Experimental Child Psychology, 130, 193-208.

Mittal, C., Griskevicius, V., Simpson, J. A., Sung, S., \& Young, E. S. (2015). Cognitive adaptations to stressful environments: When childhood adversity enhances adult executive function. Journal of Personality and Social Psychology, 109(4), 604621.

Mezzacappa, E., Buckner, J. C., \& Earls, F. (2011). Prenatal cigarette exposure and infant learning stimulation as predictors of cognitive control in childhood. Developmental Science, 14(4), 881-891.

Mistry, R. S., \& Wadsworth, M. E. (2011). Family functioning and child development in the context of poverty. The Prevention Researcher, 18(4), 11-16.

Mistry, R. S., Benner, A. D., Biesanz, J. C., Clark, S. L., \& Howes, C. (2010). Family and social risk, and parental investments during the early childhood years as predictors of low-income children's school readiness outcomes. Early Childhood Research Quarterly, 25(4), 432-449.

Muthén, L. K., \& Muthén, B. O. (2010). Mplus User's Guide: Statistical Analysis with Latent Variables: User's Guide. Muthén \& Muthén.

Parent, M. C. (2013). Handling item-level missing data: Simpler is just as good. The Counseling Psychologist, 41(4), 568-600.

Ponitz, C. E. C., McClelland, M. M., Jewkes, A. M., Connor, C. M., Farris, C. L., \& Morrison, F. J. (2008). Touch your toes! Developing a direct measure of behavioral regulation in early childhood. Early Childhood Research Quarterly, 23(2), 141-158. 
Ponitz, C. C., McClelland, M. M., Matthews, J. S., \& Morrison, F. J. (2009). A structured observation of behavioral self-regulation and its contribution to kindergarten outcomes. Developmental Psychology, 45(3), 605-619.

Raffaelli, M., Crockett, L. J., \& Shen, Y. (2010). Developmental stability and change in self regulation from childhood to adolescence. The Journal of Genetic Psychology, 166(1), 54-76.

Raikes, H. A., Robinson, J. L., Bradley, R. H., Raikes, H. H., \& Ayoub, C. C. (2007). Developmental trends in self-regulation among low-income toddlers. Social Development, 16(1), 128-149.

Raver, C. C. (2004). Placing emotional self-regulation in sociocultural and socioeconomic contexts. Child Development, 75(2), 346-353.

Raver, C. C., Blair, C., \& Garrett-Peters, P. (2015). Poverty, household chaos, and interparental aggression predict children's ability to recognize and modulate negative emotions. Development and Psychopathology, 27(03), 695-708.

Rhoades, B. L., Greenberg, M. T., Lanza, S. T., \& Blair, C. (2011). Demographic and familial predictors of early executive function development: Contribution of a person-centered perspective. Journal of Experimental Child Psychology, 108(3), 638-662.

Roid, G \& Miller, L. (1997). Leiter international performance scale-revised. Wood Dale, IL: Stoelting.

Roy, A. L., McCoy, D. C., \& Raver, C. C. (2014). Instability versus quality: Residential mobility, neighborhood poverty, and children's self-regulation. Developmental Psychology, 50(7), 1891-1896. 
Schmitt, S. A., Finders, J. K., \& McClelland, M. M. (2015). Residential mobility, inhibitory control, and academic achievement in preschool. Early Education and Development, 26(2), 189-208.

Schumaker, \& Lomax, R. E. (2004). A beginner's guide to structural equation modeling. Mahwah, NJ: Erlbaum.

Segal, M., Richter-Levin, G., \& Maggio, N. (2010). Stress-induced dynamic routing of hippocampal connectivity: A hypothesis. Hippocampus, 20(12), 1332-1338.

Sektnan, M., McClelland, M. M., Acock, A., \& Morrison, F. J. (2010). Relations between early family risk, children's behavioral regulation, and academic achievement. Early Childhood Research Quarterly, 25(4), 464-479.

Simpson, J. A., Griskevicius, V., Kuo, S. I., Sung, S., \& Collins, W. A. (2012). Evolution, stress, and sensitive periods: the influence of unpredictability in early versus late childhood on sex and risky behavior. Developmental Psychology, 48(3), 674-686.

Totsika, V., \& Sylva, K. (2004). The home observation for measurement of the environment revisited. Child and Adolescent Mental Health, 9(1), 25-35.

Tronick, E., \& Reck, C. (2009). Infants of depressed mothers. Harvard Review of Psychiatry, 17(2), 147-156.

Tsatsanis, K. D., Dartnall, N., Cicchetti, D., Sparrow, S. S., Klin, A., \& Volkmar, F. R. (2003). Concurrent validity and classification accuracy of the Leiter and Leiter-R in low-functioning children with autism. Journal of Autism and Developmental Disorders, 33(1), 23-30. 
Verma, R., Balhara, Y. P. S., \& Gupta, C. S. (2011). Gender differences in stress response: Role of developmental and biological determinants. Industrial Psychiatry Journal, 20(1), 4-10.

Vernon-Feagans, L., Willoughby, M., \& Garrett-Peters, P. (2016). Predictors of behavioral regulation in kindergarten: Household chaos, parenting, and early executive functions. Developmental psychology, 52(3), 430-441.

Von Suchodoletz, A., Trommsdorff, G., \& Heikamp, T. (2011). Linking maternal warmth and responsiveness to children's self-regulation. Social Development, 20(3), 486503.

Wallman, K. K. (2008). Federal interagency forum on child and family statistics. America's Children in Brief: Key National Indicators of Well-Being.

Wanless, S. B., McClelland, M. M., Tominey, S. L., \& Acock, A. C. (2011). The influence of demographic risk factors on children's behavioral regulation in prekindergarten and kindergarten. Early Education \& Development, 22(3), 461488. 


\section{Appendices}

Table 1

Descriptive Statistics and Bivariate Relationships $(N=966)$

Variable

Variable $M(S D) \%$ Missing

1. Ethnicity

2. Child sex ${ }^{b}$

3. Program group ${ }^{c}$

4. Maternal marital transitions

$43(.49)$

0.03

\begin{tabular}{lllllllllllllll}
1 & 2 & 3 & 4 & 5 & 6 & 7 & 8 & 9 & 10 & 11 & 12 & 13 & 14 & 15 \\
\hline
\end{tabular}

5. Maternal employment transition

$\begin{array}{rll}.51(.50) & 0.09 & -.071^{*}\end{array}$

$.52(.50)$

$.51(.69)$

$95(.98)$

$95(.98)$

$.70(.46)$

$.53(.43)$

$.05(.96)$

$.43(.50)$

$.02(.99)$

$.08(1.0)$

$.08(1.0)$

$.074(.94)$

$8.67(1.9)$

$\begin{array}{lll}0.00 & 0.026 & -0.045\end{array}$

$\begin{array}{llll}0.02 & .079 * & 0.035 & 0.048\end{array}$

$\begin{array}{llllll}0.00 & -0.054 & -0.005 & -0.030 & 064 *\end{array}$

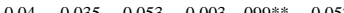

$\begin{array}{lllllll}0.00 & -0.024 & 0.010 & 0.007 & .103 * * & .160 * * & .097 * *\end{array}$

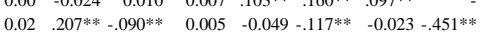

$\begin{array}{llllllll}0.06 & .131 * * & -0.062 & -0.024 & -0.092 * * & -.067 * & -0.024 & -.457 * * \\ 0.06 & .023\end{array}$

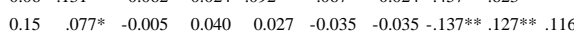

10. Maternal warmth

$\begin{array}{llllllll}0.20 & .266 * * & -.080 * & 0.010 & 0.016 & -0.057 & 0.012-.183 * * .288^{* *} .219^{* *} .283 * *\end{array}$

12. Cognitive stimulation

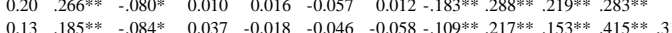

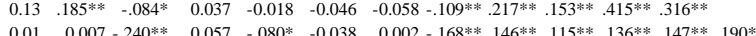

13. LEITER-R attentio

$8.45(1.8)$

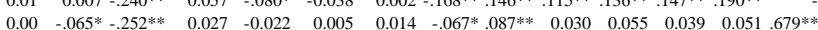

15. LEITER-R emotion regulation

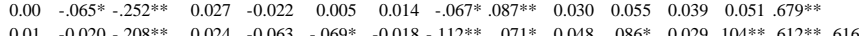

**. Correlation is sign

a $1=$ Euopean American, $0=$ Hispanic and African American

${ }^{\mathrm{b}} 0=$ Female, $1=$ Male

${ }^{\mathrm{c}} 0=$ Control, $1=$ Early Head Start

${ }^{\mathrm{d}} 0=$ Did not move, $1=$ Moved

${ }^{\mathrm{e}} 0=$ Below poverty line, $1=$ Above poverty line 
Table 2

Multiple Group Analyses

\begin{tabular}{llllllll}
\hline & \multicolumn{3}{c}{ Alternative Model } & \multicolumn{4}{c}{ Null Model } \\
\cline { 2 - 8 } Group & $\chi^{2}$ & CFI & RMSEA & $\chi 2$ & CFI & RMSEA & $\chi^{2}$ DIFFTEST \\
\hline 1. Child sex & 119.63 & 0.987 & 0.023 & 148.47 & 0.977 & 0.029 & $23.801^{*}$ \\
2. Ethnicity & 152.94 & 0.967 & 0.036 & 194.77 & 0.950 & 0.042 & $35.475^{* * *}$ \\
\hline
\end{tabular}

* Significant at the 0.05 level.

*** Significant at the 0.001 level. 


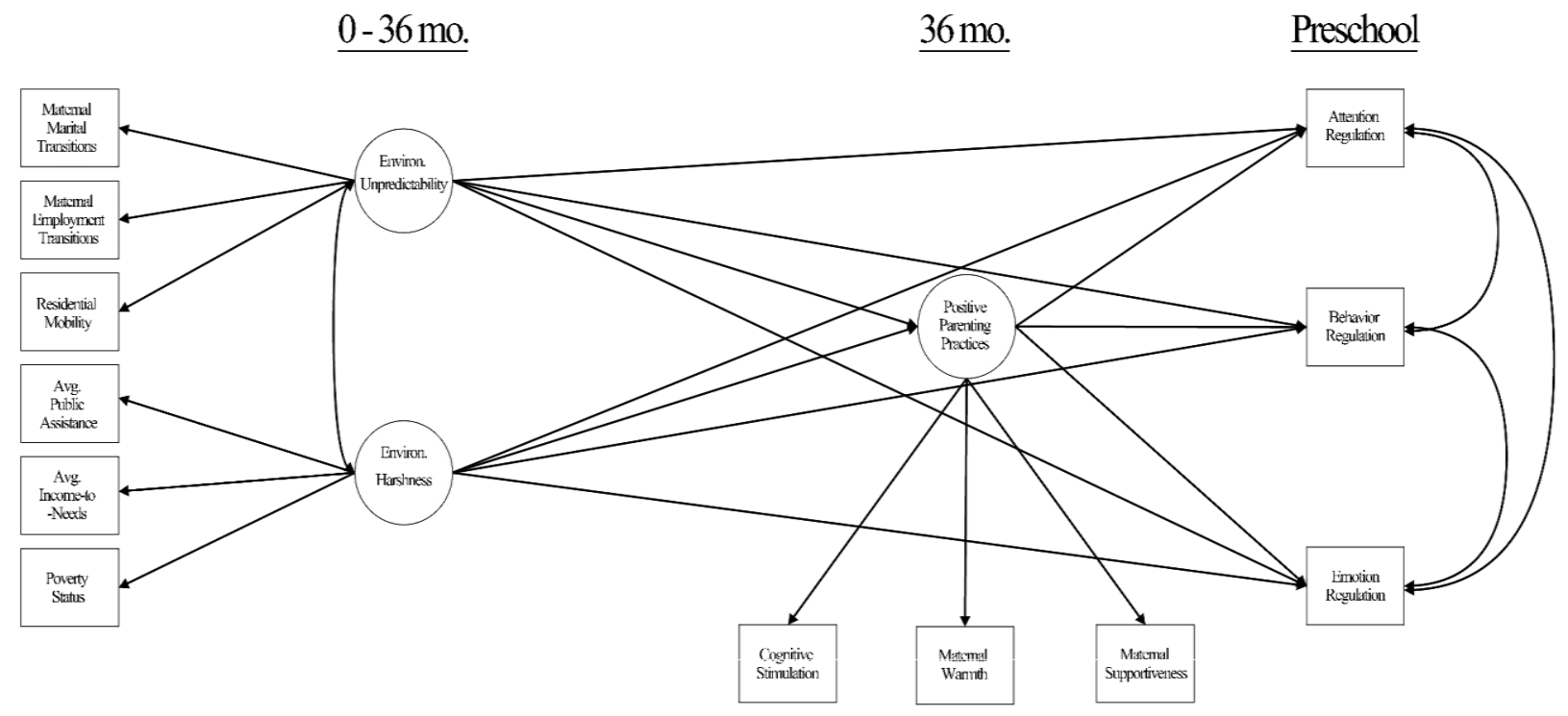

Figure 1. The conceptual model. 


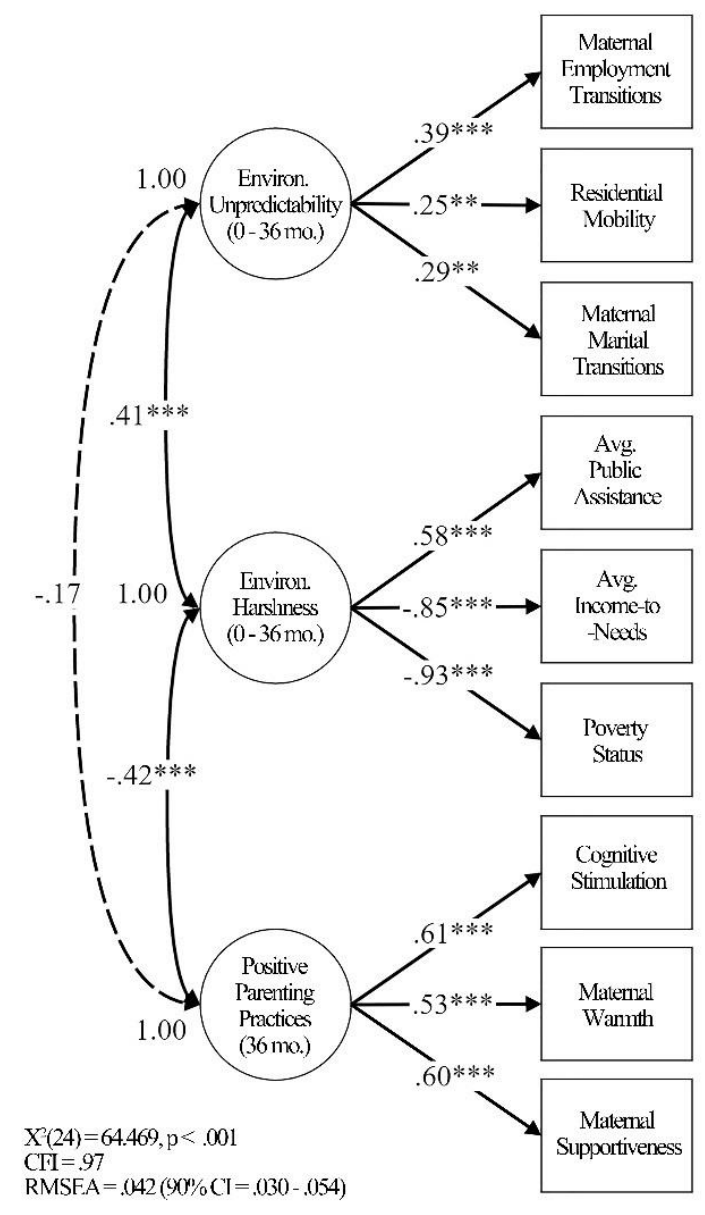

Figure 2. The measurement model. CFI = comparative fit index, RMSEA = root-meansquare error of approximation. $* p<.05, * * p<.01, * * * p<.001$. Dashed paths are nonsignificant. 


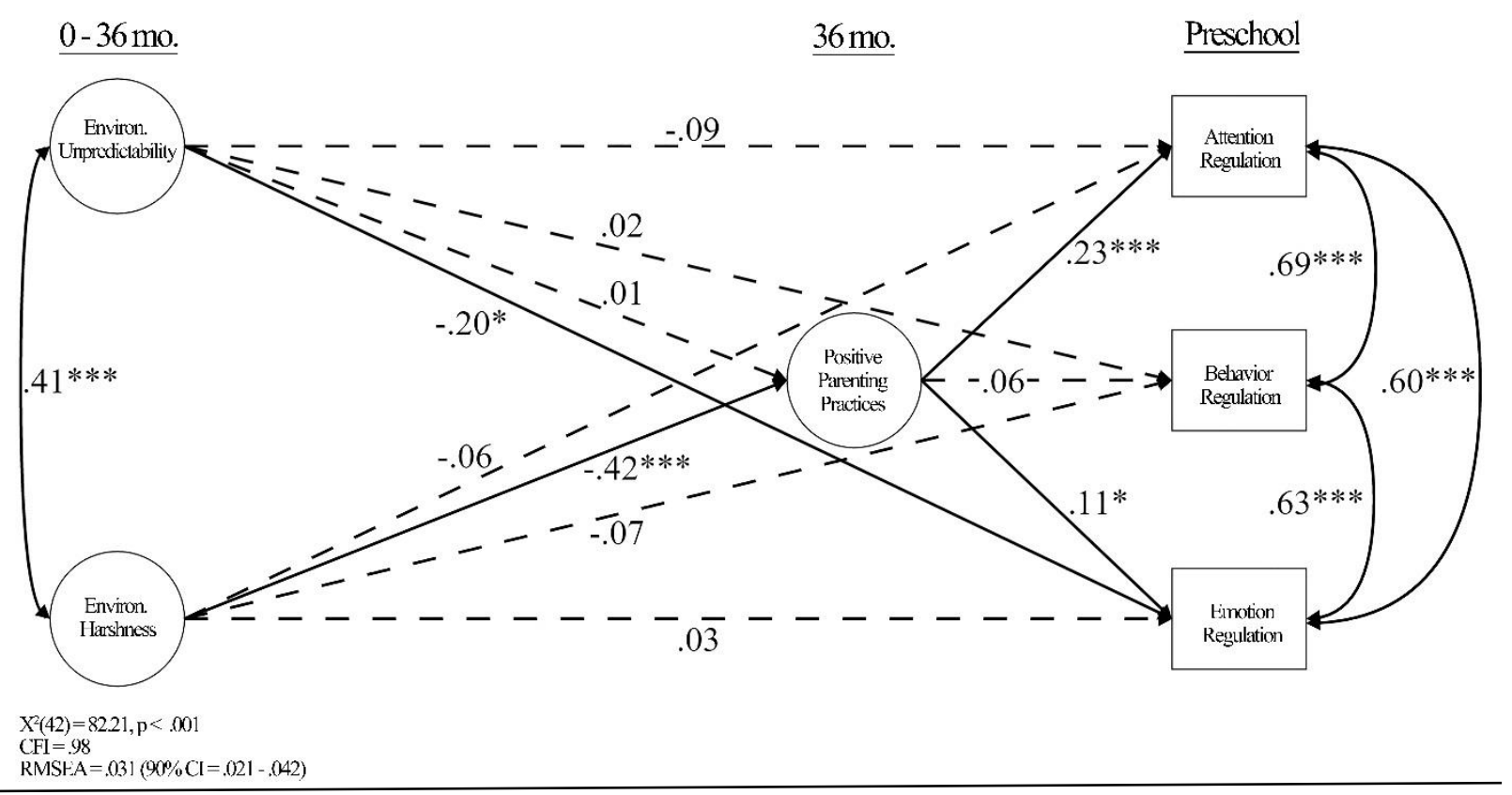

Figure 3. The analysis model. CFI $=$ comparative fit index, RMSEA $=$ root-mean-square error of approximation. $* p<.05, * * p<.01,{ }^{* * *} p<.001$. Dashed paths are nonsignificant. 


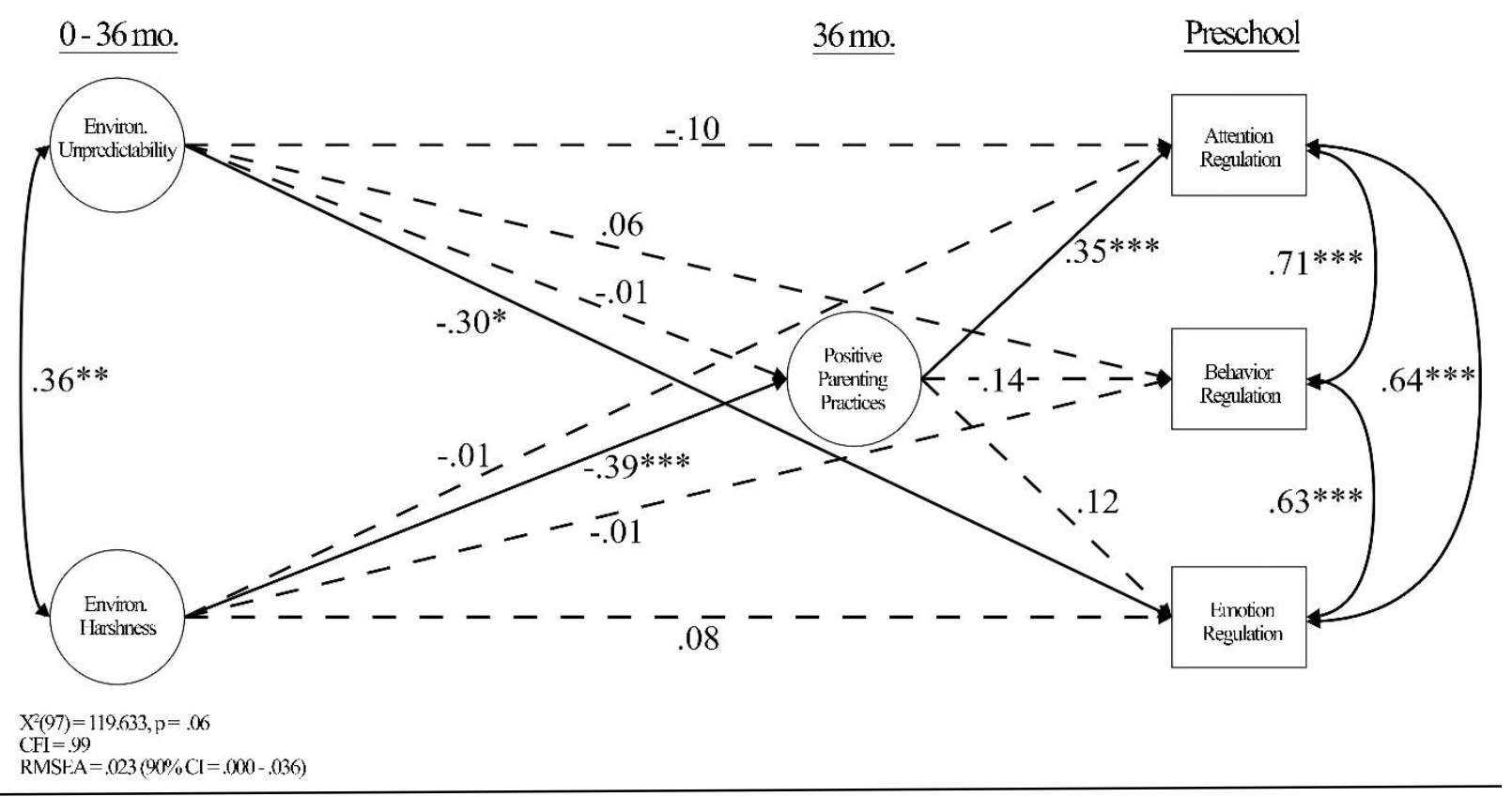

Figure 4. The analysis model for boys. CFI = comparative fit index, RMSEA = rootmean-square error of approximation. $* p<.05, * * p<.01, * * * p<.001$. Dashed paths are non-significant. 


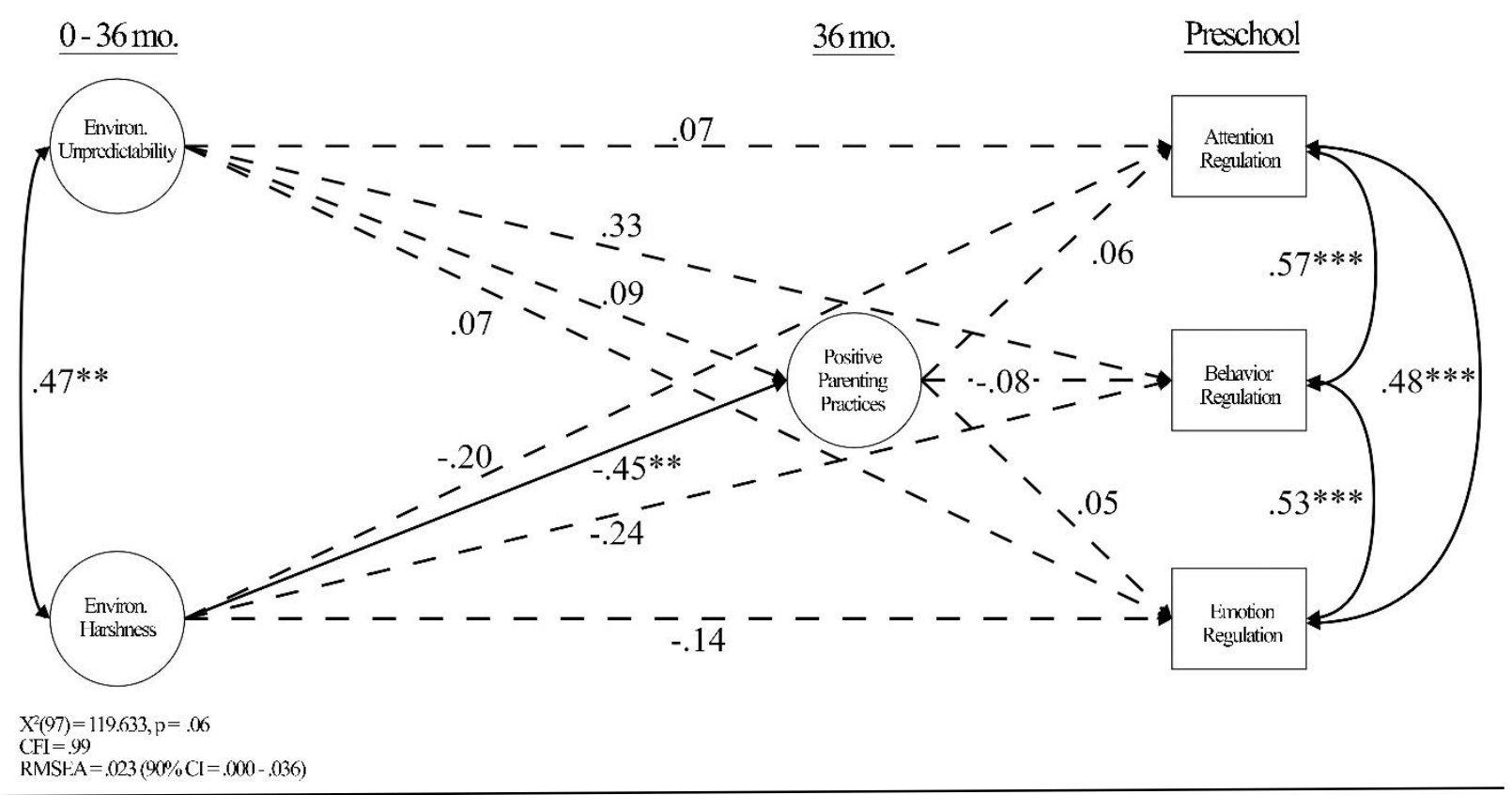

Figure 5. The analysis model for girls. $\mathrm{CFI}=$ comparative fit index, RMSEA $=$ rootmean-square error of approximation. $* p<.05$, ** $p<.01, * * * p<.001$. Dashed paths are non-significant. 


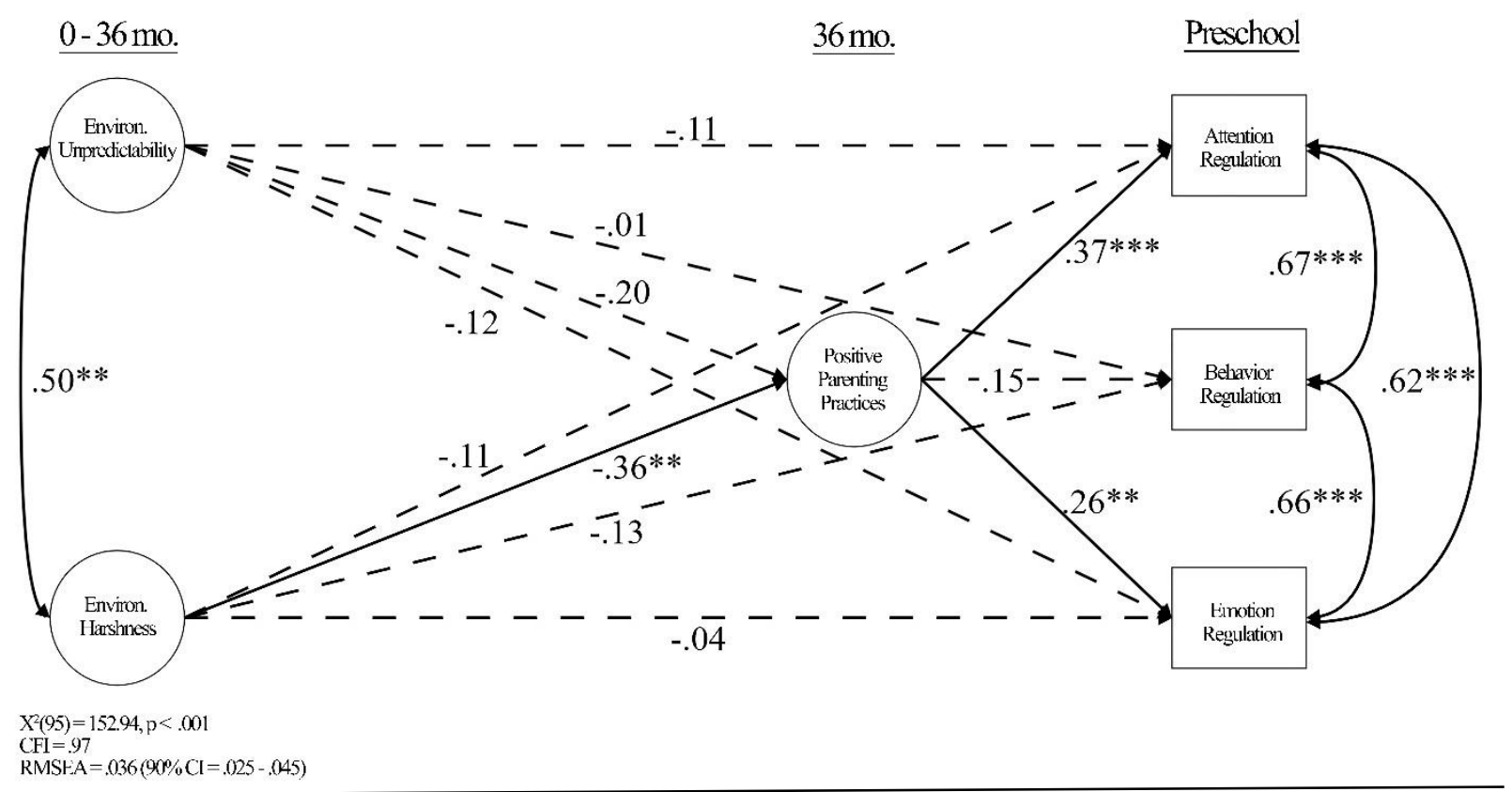

Figure 6. The analysis model for European Americans. CFI = comparative fit index, RMSEA = root-mean-square error of approximation. ${ }^{*} p<.05, * * p<.01, * * * p<.001$. Dashed paths are non-significant. 


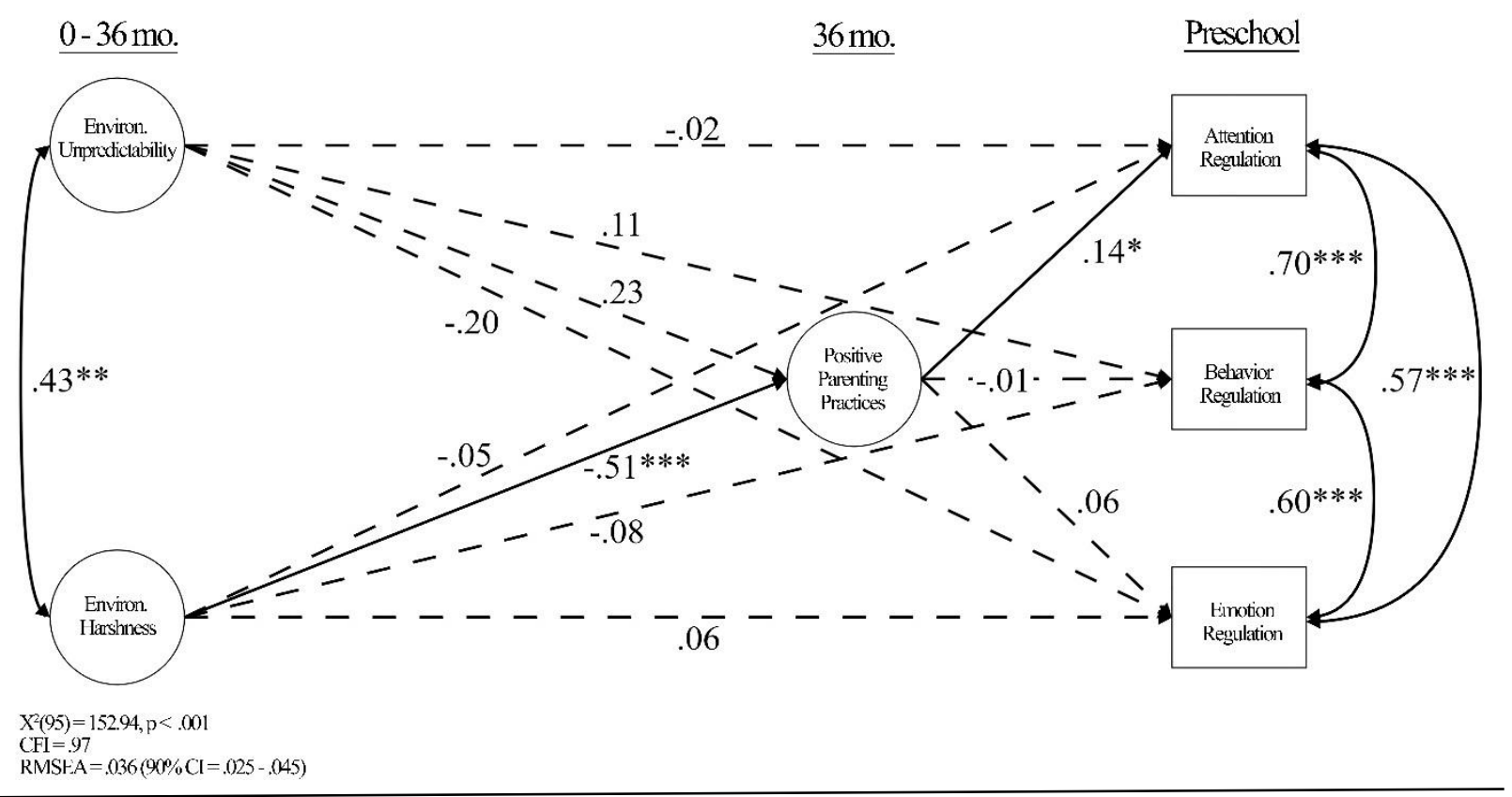

Figure 7. The analysis model for African Americans and Hispanics. CFI $=$ comparative fit index, RMSEA = root-mean-square error of approximation. $* p<.05$, ** $p<.01$, *** $p<.001$. Dashed paths are non-significant. 
Christina Squires was born in Fresno, California and received her undergraduate degree in Child Development from California State University, Fresno. She completed her Master's and PhD in Human Development and Family Science at the University of Missouri, Columbia. Her research broadly examines children's cognitive development and focuses specifically on exploring the development, acquisition, and use of selfregulation during the early childhood years. Much of her research is devoted to understanding developmental processes among low-income and at-risk children, and she is particularly interested in the role of socioeconomic contexts on children's selfregulation, as well as the influence of homelessness on children's development. Her research on these topics has been published in The Journal of Educational Research and presented at several national and local conferences, including the Society for Research in Child Development, Association for Psychological Science, National Research Conference on Early Childhood, and the Homelessness Awareness Conference. 